\title{
Nonvisual Navigation by Blind and Sighted: Assessment of Path Integration Ability
}

\author{
Jack M. Loomis, Roberta L. Klatzky, Reginald G. Golledge, \\ Joseph G. Cicinelli, James W. Pellegrino, and Phyllis A. Fry
}

\begin{abstract}
Blindfolded sighted, adventitiously blind, and congenitally blind subjects performed a set of navigation tasks. The more complex tasks involved spatial inference and included retracing a multisegment route in reverse, returning directly to an origin after being led over linear segments, and pointing to targets after locomotion. As a group, subjects responded systematically to route manipulations in the complex tasks, but performance was poor. Patterns of error and response latency are informative about the internal representation used; in particular, they do not support the hypothesis that only a representation of the origin of locomotion is maintained. The slight performance differences between groups varying in visual experience were neither large nor consistent across tasks. Results provide little indication that spatial competence strongly depends on prior visual experience.
\end{abstract}

Effective navigation by humans involves a number of skills, including updating one's position and orientation during travel, forming and making use of representations of the environment through which travel takes place, and planning routes subject to various constraints (shortest distance, minimal travel time, maximum safety, etc.); see Rieser, Guth, and Hill (1982); Strelow (1985). Methods of updating position and orientation can be classified according to the type of information used: position, velocity, or acceleration. Position-based navigation (called pilotage or piloting) relies on external signals indicating the observer's position and orientation (Baker, 1981; Etienne, 1992); such signals would include visible or audible landmarks known to the traveler or those from electronic navigation aids. Velocity-

Jack M. Loomis and Roberta L. Klatzky, Department of Psychology, University of California, Santa Barbara; Reginald G. Golledge, Department of Geography, University of California, Santa Barbara; Joseph G. Cicinelli, Commercial Flight Systems Group, Honeywell, Inc., Phoenix, Arizona; James W. Pellegrino, Department of Psychology, Peabody College, Vanderbilt University; Phyllis A. Fry, Social Science Computing Center, Swarthmore College.

This research was supported primarily by Grant 7022 from the National Eye Institute; additional funds were provided by the Academic Senate and the Office of Research Development of the University of California, Santa Barbara.

We are especially grateful to the Los Angeles branch of the Braille Institute of America for providing research space during an extended period and for assistance in locating subjects. We also thank the local branch of the Braille Institute for assistance in locating subjects in the Santa Barbara area. We express our appreciation to Robert Perrone, an orientation and mobility instructor at the Braille Institute in Los Angeles, for his assistance with the locomotion tasks. We also thank John Rieser for providing details of the procedure used in the experiment by Rieser, Guth, and Hill (1986), Chick Hebert for technical assistance, Sally Doherty for logistic help in arranging the Los Angeles study, and Karen Harp and Xiao Li Yang for help in running the experiments.

Correspondence concerning this article should be addressed to Jack M. Loomis, Department of Psychology, University of California, Santa Barbara, California 93106. based navigation (called dead reckoning or path integration) requires external signals indicating the traveler's instantaneous speed and direction of travel (Mittelstaedt \& Mittelstaedt, 1982; Schiesser, 1986); linear and rotary displacements with respect to initial position and orientation are computed by integrating the linear and rotary components of self-velocity. Proprioception, optical flow, and acoustical flow are among the signals available for sensing self-motion. With acceleration-based navigation (called inertial navigation or, sometimes, path integration), linear and rotary accelerations of the traveler are doubly integrated to obtain linear and rotary displacements with respect to the initial position and orientation (Barlow, 1964; Pitman, 1962; Potegal, 1982, 1985; Schiesser, 1986). This does not require external sensing; the vestibular system in humans and other species provides information about linear acceleration and rotational velocity and acceleration (Barlow, 1964; Howard, 1982). Ordinary human ambulation undoubtedly makes use of all three types of information. (For an excellent general reference, see Gallistel, 1990).

Independent of the type of information used for updating position and orientation, the human traveler usually must also have access to some representation of the space through which travel is occurring. For travel over large unfamiliar distances, an external representation or map is essential. Our concern here is with navigation without sight over smallscale space, where the traveler must rely on some form of internal representation of the environment or of the travel path.

\section{Nonvisual Navigation}

This focus of our work stems from an interest in the more general problem of how blind travelers make their way through natural environments. Clearly, blind travelers are at a considerable disadvantage relative to the sighted, for vision ordinarily provides information about both the trave!er's motion and the layout of near and far space (Foulke, 1971, 1982; Strelow, 1985; Welsh \& Blasch, 1980). For the congenitally blind, there is the possibility that they are even 
more disadvantaged if visual experience is required for the development of normal spatial ability. Our work is directed toward a better understanding of two questions: (a) What are the internal processes necessary for successful nonvisual navigation, and (b) does past visual experience contribute to nonvisual navigation ability?

The experiments described here generally involved locomotion over short paths (less than $20 \mathrm{~m}$ ) through environments possessing no position cues (landmarks). Because we eliminated visual and auditory position cues, subjects had only proprioceptive and inertial cues available for sensing self-motion, from which they could update their positions and orientations by integration. As we did earlier, we refer to this mode of navigation as path integration. Although the limited range of travel and the inaccessibility of position information mean that our subjects were not confronted with the challenge that blind people face in everyday travel, we believe that the simplified tasks are informative about some of the processes involved in navigation without vision and about the role of prior visual experience in the development of spatial ability.

We now consider the components of navigation without vision in more detail. To account for the range of navigational tasks and the various sources of error that can occur, we propose that navigation subsumes five general processes (one or more of which could be absent in any particular situation). They are (a) sensing, (b) creating a trace of the route, (c) forming a survey representation of the disposition or layout of spatial features, (d) computing desired trajectories, and (e) executing those trajectories. The first process, sensing, refers to the acquisition of information about selfmotion or landmarks, or both, in any sensory modality (e.g., vision, hearing, proprioception). The trace of the route could be a sensory record, or it could be more abstract, as is generally implied by the term route representation. In any case, it depicts a sequence of contiguous segments and turns, subject to perceptual distortion and memory loss. The third general process uses information from traveling a route to compute a representation of the spatial disposition (direction and distance) of route features, without constraints on contiguity; this is often called a survey representation (although we make no assumption that it is an image). Features included could be objects encountered and salient pathway points such as pivot locations. By means of the fourth general process, desired trajectories can be computed, based on either the survey representation or the trace of a route. The fifth process is then responsible for output.

Implicit in this treatment is the possibility of computing one representation from another by way of inference rules. It is important to realize, however, that people may not be able to compute all that is logically implied by spatial information that they have in memory. For example, it is logically possible to infer the relative spatial disposition of all pivot points along a route from a specification of segment lengths and turn values. However, people are generally unable to do this, instead requiring experience with the direct relations between the points. Indeed, it is known that adults compartmentalize their spatial knowledge in the form of distinct representations of the same environment
(Kuipers, 1978, 1982; Lynch, 1960). This compartmentalization may result in people's holding spatial beliefs that are inconsistent, without any awareness of the inconsistency.

As mentioned earlier, a traveler can update position by means of path integration, that is, using either proprioceptive or inertial cues and integrating as necessary to determine displacement and heading change. (For research revealing different functional properties of the proprioceptive and inertial processing mechanisms in the human, see Mittelstaedt \& Glasauer, 1991.) For ambulating species (cf. swimming or flying), path integration is usually meant to refer to a step-by-step updating of position with respect to some coordinate system; thus the trace of the history of travel is limited to the most recent footstep or turn. This is used to compute a very simple representation of spatial disposition, namely, that between the traveler and just one other point, such as the origin of travel (Müller \& Wehner, 1988). At a minimum, the traveler can be said to compute a homing vector specifying the distance and relative direction to the reference point (Fujita, Loomis, Klatzky, \& Golledge, 1990 ), thus qualifying it as a survey representation, albeit a minimal one. The representation directly indicates the desired straight path from the traveler to the reference point. This type of representation is history free, for only the current homing vector is retained in memory. The desert ant (Müller \& Wehner, 1988; Wehner \& Wehner, 1986) and several species of geese (Mittelstaedt \& Mittelstaedt, 1982; von Saint Paul, 1982) successfully use this approach to navigation when visual landmarks are lacking; however, their ability to perform path integration over hundreds of meters depends on the use of visual information in sensing self-motion.

The homing-vector model is particularly useful because it makes assumptions to which those of other models can be compared. An alternative to step-by-step updating is to encode positional or directional change over a more extended time period and hence to maintain a record of multiple segments of the traveled route in memory. One indication that humans navigating without vision update at longer intervals than a footstep is that in estimating or reproducing linear distance, subjects tend to overestimate short distances and underestimate long ones (Klatzky, Loomis, Golledge, Cicinelli, et al., 1990). If there were step-by-step updating, subjects would have no differential trace of travel depending on total distance. Errors would occur at the footstep level, and the ratio of represented to actual distance would have to remain constant over distance traveled.

With the foregoing analysis in mind, we make an important distinction between types of navigation tasks, according to the nature of the representation required. We distinguish tasks that merely require reproduction or estimation, or both, from those that require computation of a new trajectory. Within each of these categories, further distinctions can be made, depending on the complexity of the information provided and the computation to be performed. Reproduction of a simple route could be based on just a memory trace of the route. Any response that is more complex requires processing beyond this route representation, such as forming a survey representation by spatial inference or comput- 
ing a new trajectory. For example, to retrace a route in reverse requires reversing the sequence of distances and both the sequence and direction of turns; for this task the stored trace will not be sufficient. Taking a shortcut requires building a survey representation and computing a completely new pathway (assuming there is no step-by-step updating; see earlier).

\section{Role of Visual Experience in Navigation Ability}

We turn now to possible navigation differences between blind and sighted individuals, under circumstances where the latter are denied vision. From some research findings, at least, it appears that prior visual experience has consequences for tasks performed without vision. It has been observed that blindfolded sighted or adventitiously blind subjects perform better than congenitally blind subjects on a variety of navigation tasks. In a much cited study, Worchel (1951) had subjects complete the third legs in isosceles right triangles varying in size. Triangle completion is a task that, in principle, can be carried out by path integration, without the need for representing the traversed pathway in memory; it is widely used in both human and animal research (e.g., Beritoff, 1965; Landau, Spelke, \& Gleitman, 1984; Müller \& Wehner, 1988; Yamamoto, 1991). Worchel found that the sighted observers performed significantly better than the blind subjects; somewhat surprisingly, congenitally and adventitiously blind observers did not perform differently. A more complex navigation task was devised by Rieser, Guth, and Hill (1986); unlike triangle completion, it required having a survey representation of the relative disposition of two or moré locations. Blindfolded, early blind, and late-blind subjects were familiarized with the layout of objects in space by being led several times between each object and a fixed home location. After familiarization, subjects in the locomotion condition were led to one of the targets and then were asked to point toward each of the others; in the imagination condition, they were asked to imagine being at that same target (while standing at home) and to point to the other targets. Sighted and late-blind subjects did considerably better in the locomotion condition than in the imagination condition; in contrast, the early blind subjects showed little difference in performance between the two conditions and performed with much higher error rates when pointing in both of these conditions than when pointing from the home location.

The influence of visual status has been observed in a variety of other studies. In a comparison of congenitally and adventitiously blind children on a task involving pointing to known locations while traveling over a known route, Dodds, Howarth, and Carter (1982) found that some of the congenitally blind children performed extremely poorly. In another study involving large-scale space, Rieser, Hill, Talor, Bradfield, and Rosen (1992) found that both congenitally blind subjects and those who had suffered large-field losses early in life exhibited poorer knowledge of the spatial disposition of landmarks within their communities than the other subject groups (sighted, adventitiously blind, and those suffering early acuity loss but not large-field loss). Similarly,
Casey (1978) found that the congenitally blind were less accurate in creating tactual maps of their school campus than those blinded later in life. Finally, Rieser, Lockman, and Pick (1980) found that the congenitally blind estimated Euclidean distances between locations within a familiar building with significantly less accuracy than the adventitiously blind and sighted even though the three groups performed approximately the same in estimating the functionai (walking) distances between these locations. A number of other studies have shown poorer performance by the blind, both on navigation tasks and on spatial abilities tasks using stimuli within the range of a tabletop (Brambring, 1976; Byrne \& Salter, 1983; Dodds \& Carter, 1983; Heller \& Kennedy, 1990; Herman, Chatman, \& Roth, 1983; Hollins \& Kelley, 1988; Kerr, 1983; Lederman, Klatzky, \& Barber, 1985; Millar, 1976, 1981; Rieser, 1990; Veraart \& WanetDefalque, 1987).

Support for the opposite view, that the congenitally blind are not impaired significantly in spatial ability relative to the sighted, comes from several studies. Passini, Proulx, and Rainville (1990) compared sighted, congenitally blind, and adventitiously blind subjects on eight wayfinding tasks in a labyrinthian layout. The congenitally blind subjects tended to perform better than the other groups. Beritoff (1965) claimed that blind children were superior to sighted children at retracing routes they had traveled only once. Hollins and Kelley (1988) found that congenitally blind observers performed a tabletop version of the Rieser et al. (1986) task as well as blindfolded sighted observers when asked to replace an object on the table after having walked partly around the table. They interpreted this result to mean that blind observers are able to perform spatial updating as well as the sighted. Using a pointing response instead, Hollins and Kelley found that blind observers showed poorer performance than the sighted, but they argued that the greater errors were due to distorted recall of the stimulus field, not to an inability to perform spatial updating. In another tabletop variant of the Rieser task, Barber and Lederman (1988) similarly found no deficits in the blind groups. Heller and Kennedy (1990) compared groups of observers performing a variant of the Piagetian three-mountain task, in which they had to identify or draw raised pictures of three objects from novel vantage points after having felt them from an initial location. The congenitally blind observers performed the two tasks with nearly the same accuracy as the sighted and adventitiously blind groups but did so with much longer latencies. Finally, Landau and colleagues (Landau, 1988; Landau, Spelke, \& Gleitman, 1984) found that a young congenitally blind child could take shortcuts between familiar locations within a room (but see Liben, 1988, for a comment). We should note also that some of the studies cited earlier showing poorer performance by the blind in some tasks found no performance differences on other tasks (e.g., Byrne \& Salter, 1983).

The existence of results showing that the blind perform worse than the sighted have prompted some to suggest that visual experience promotes or is even necessary for the development of normal spatial competence (Bower, 1977, p. 160; Foulke, 1982; Senden, 1960). However, the total evi- 
dence is more than adequate to reject the stronger version of this claim, for in most tests of spatial ability there are congenitally blind individuals who perform as well as the average sighted subjects. What about the weaker claim that visual experience is a factor in the degree to which spatial ability develops? There is no doubt that a number of the tasks mentioned earlier show clear differences between those with and those without visual experience; moreover, the subjects exhibiting the poorest performance in many tasks are congenitally blind. The existing research, however, is not unequivocal, and it establishes no clear pattern indicating where performance differences should be observed.

One hypothesis is that differences between blind and sighted will increase with the complexity of the spatial inference required by a task. Thus, tasks requiring a subject to compute a survey representation or a novel route, or both, might show effects of visual status, whereas tasks based directly on the trace of travel, such as reproduction of a route, would not. That these tasks have different difficulty levels is indicated by the results of Klatzky, Loomis, Golledge, Cicinelli, Doherty, and Pellegrino, (1990), with sighted, blindfolded individuals. The subjects were able to reproduce quite accurately linear segments and turns after guided locomotion. However, performance was substantially worse when subjects were required to execute shortcuts back to the origin of a multisegment pathway, especially if one of the segments crossed an earlier segment.

The present experiment compared the performance of sighted, adventitiously blind, and congenitally blind in two classes of navigation tasks, in both of which subjects moved about within a 12 -m-square work space. The simple locomotion tasks required subjects to produce, reproduce, or estimate a single turn or distance. Because these tasks could be performed on the basis of temporal, kinesthetic, and vestibular information about the route, they were assumed to require minimal use of inferential processes. ${ }^{1}$ In contrast, the complex navigation tasks were those that we have suggested require computation of a new trajectory. These tasks required subjects to retrace a multisegment route in the reverse direction, to produce a shortcut back to the origin of locomotion after traversing two or three outbound legs, or to point to one location from a second location when the two were known by the subject only in terms of their dispositions relative to a third location (Rieser et al., 1982, 1986).

\section{Experiment 1}

\section{Method}

Subjects. The subject population is described in Table 1. Most of our blind subjects were recruited with the assistance of the Los Angeles Braille Institute; those that were not lived in Santa Barbara, California, and were referred to us by the local Braille Institute or through personal contacts. All of our subjects were capable of finding their way around in their communities (by walking, public transportation, or both); most were employed or were college students. The three groups (sighted, congenitally blind, and adventitiously blind) were approximately matched in composition in terms of age and educational level. Each subject received payment for participation in the experiment, which lasted about $4 \mathrm{hr}$ including rest periods.

General. The study made use of tabletop tasks, which used stimuli manipulated by hand and simple and complex tasks involving locomotion. Different experimenters conducted the tabletop and locomotion tasks. The tabletop tasks will be described in a separate article (Klatzky, Golledge, Loomis, Cicinelli, \& Pellegrino, 1993). The simple locomotion tasks were reproducing and estimating a walked distance and reproducing and estimating a turn. The complex locomotion tasks were completing a triangle after walking two legs and either retracing in reverse a two- or three-sided figure or completing it with a shortcut. (Subjects' veering tendencies were also assessed but are not reported here.) The session always began with an interview and the tabletop tasks. The simple locomotion, triangle completion, and retracecompletion tasks occurred in a counterbalanced order across subjects. Within the simple locomotion task, the order of individual tests was also counterbalanced, although all three tests occurred as a block. The interview and tabletop tasks took approximately 30-45 min, simple locomotion took $30 \mathrm{~min}$, triangle completion took $1.5 \mathrm{hr}$, and completion and reproduction took $1 \mathrm{hr}$. Subjects were given a break after the first locomotion task, midway through the triangle completion task (when cameras were recalibrated; see later), following triangle completion, and on request.

The locomotion tests were conducted in a darkened room that provided a work area $12 \mathrm{~m} \times 12 \mathrm{~m}$. Lights were used to illuminate the room sufficiently for the experimenters to instruct and guide the subjects. Subjects were blindfolded throughout and wore sound-attenuating headphones, on which were mounted two $6.5-\mathrm{V}$ bulbs that were connected to a battery pack worn at the waist. Two video cameras mounted at right angles along the sides of the work space were connected to a $12-\mathrm{MHz} 286$ computer, which tracked the angular positions of the bulbs at a rate just under $6 \mathrm{~Hz}$. The two-dimensional coordinates of the light source were computed by a triangulation algorithm, which provided absolute positional accuracy (in work space coordinates) to within 7 $\mathrm{cm}$; relative positional accuracy was on the order of $2 \mathrm{~cm}$. Further details are reported in Klatzky, Loomis, Golledge, Cicinelli, et al. (1990).

Simple locomotion: distance estimation and reproduction. The subject was led by sighted-guide technique (i.e., holding onto the upper arm of the experimenter, who walked beside the subject) for $2,4,6,8$, or $10 \mathrm{~m}$. The five distances were tested in random order. Verbalization was suppressed by having the subject repeat a nonsense phrase while walking. After traversing a given distance, the subject verbally estimated it, using a previously established 2-m standard (which the subject had been trained to re-

\footnotetext{
${ }^{1}$ It is possible that reproduction overestimates the adequacy of the trace of a route, if errors in route representation are compensated for during reproduction. For example, a subject who misperceives distance might judge that a linear segment of $3 \mathrm{~m}$ is only 2 $m$ long. On attempting to reproduce the response, however, the subject might terminate the response on the basis of the same information used when he or she was passively led over the stimulus path; thus, the subject might walk $3 \mathrm{~m}$ to perceive having moved a distance of $2 \mathrm{~m}$. In this way, the response might be far more accurate than in the case where the subject carries out a preprogrammed response without monitoring its perceptual consequences. Klatzky, Loomis, Golledge, Cicinelli, et al. (1990) used both reproduction and estimation and found that errors were quite similar in the two cases, suggesting that reproduction provides a good indication of what the subject has perceived and encoded.
} 
Table 1

Subject Characteristics in Main Experiment

\begin{tabular}{|c|c|c|c|c|c|}
\hline Subject & Age & Gender & Education & Years blind & Cause \\
\hline \multicolumn{6}{|c|}{ Congenitally blind } \\
\hline 1 & 36 & $\mathrm{~F}$ & AA & 35 & RLF \\
\hline 2 & 38 & M & $\mathrm{BA}$ & 38 & $\mathrm{G}$ \\
\hline 3 & 36 & $M$ & $\mathrm{AA}$ & 35 & RLF \\
\hline 4 & 30 & $\mathrm{~F}$ & $\mathrm{AA}$ & 30 & U \\
\hline 5 & 33 & $\mathrm{~F}$ & $\mathrm{BA}$ & 31 & RB \\
\hline 6 & 42 & $\mathrm{~F}$ & MA & 42 & $\mathrm{RD}$ \\
\hline 7 & 54 & $\mathrm{M}$ & HS & 54 & $\mathrm{U}$ \\
\hline 8 & 42 & M & $\mathrm{AA}$ & 42 & RLF \\
\hline 9 & 41 & $\mathrm{M}$ & MA & 39 & $\mathrm{U}$ \\
\hline 10 & 42 & M & $\mathrm{BA}$ & 42 & RLF \\
\hline 11 & 18 & M & HS & 18 & $\mathrm{CC}$ \\
\hline 12 & 29 & $\mathrm{~F}$ & $\mathrm{BA}$ & 28 & $\mathrm{RB}$ \\
\hline \multicolumn{6}{|c|}{ Adventitiously blind } \\
\hline 1 & 55 & $\mathrm{~F}$ & MA & 2 & RP \\
\hline 2 & 49 & M & $\mathrm{BA}$ & 3 & $\mathrm{RP}$ \\
\hline 3 & 32 & $\mathrm{~F}$ & AA & 1 & $\mathrm{DR}$ \\
\hline 4 & 45 & $\mathrm{M}$ & HS & 1 & $\mathrm{RP}$ \\
\hline 5 & 51 & $\mathrm{~F}$ & Grade 7 & 44 & $\mathrm{M}$ \\
\hline 6 & 49 & $\mathrm{M}$ & $\mathrm{AA}$ & 43 & $\mathrm{RP}$ \\
\hline 7 & 56 & $\mathrm{~F}$ & $\mathrm{AA}$ & 8 & $\mathrm{DR}$ \\
\hline 8 & 37 & $\mathrm{~F}$ & $\mathrm{BA}$ & 34 & $\mathrm{G}$ \\
\hline 9 & 46 & $\mathrm{~F}$ & $\mathrm{HS}$ & 33 & G \\
\hline 10 & 48 & $\mathrm{M}$ & MA & 30 & G \\
\hline 11 & 59 & $M$ & $\mathrm{AA}$ & 18 & $\mathrm{U}$ \\
\hline 12 & 32 & $\mathrm{M}$ & BA & 22 & $\mathrm{G}$ \\
\hline 13 & 53 & $\mathrm{~F}$ & $\mathrm{AA}$ & 35 & RP \\
\hline \multicolumn{6}{|c|}{ Sighted } \\
\hline 1 & 40 & M & BA & - & - \\
\hline 2 & 45 & $\mathrm{M}$ & $\mathrm{AA}$ & - & - \\
\hline 3 & 42 & F & $\mathrm{BA}$ & - & - \\
\hline 4 & 57 & $\mathrm{~F}$ & HS & - & - \\
\hline 5 & 28 & F & MA & - & - \\
\hline 6 & 40 & $\mathrm{M}$ & MA & - & - \\
\hline 7 & 56 & $M$ & $\mathrm{BA}$ & - & - \\
\hline 8 & 39 & $M$ & $\mathrm{MA}$ & - & - \\
\hline 9 & 32 & $\mathrm{M}$ & $\mathrm{MA}$ & - & - \\
\hline 10 & 40 & F & $\mathrm{BA}$ & - & - \\
\hline 11 & 59 & $\mathrm{~F}$ & $\mathrm{AA}$ & - & - \\
\hline 12 & 41 & $\mathrm{M}$ & $\mathrm{MA}$ & - & - \\
\hline
\end{tabular}

Note. $\mathrm{F}=$ female: $\mathrm{M}=$ male: $\mathrm{AA}=$ Associate of Arts: $\mathrm{BA}=$ Bachelor of Arts: $\mathrm{MA}=$ Master of Arts; $\mathrm{HS}=$ high school: $\mathrm{RLF}=$ retrolental fibroplasia $\mathrm{G}=$ glaucoma; $\mathrm{U}=$ unknown; $\mathrm{RB}=$ retinoblastoma: $\mathrm{RD}=$ retinal detachment: $\mathrm{CC}=$ congenital coloboma; $\mathrm{DR}=$ diabetic retinopathy; $\mathrm{RP}=$ retinitis pigmentosa: $\mathrm{M}=$ measles.

produce) as the unit of measure. The distance was then reproduced by walking forward without aid.

Simple locomotion: Tum estimation and reproduction. The subject grasped the ends of handlebars and was led straight for approximately $3 \mathrm{~m}$ and then through a turn of $60^{\circ} .90^{\circ}, 135^{\circ}$, $180^{\circ} .225^{\circ}, 270^{\circ}$. or $300^{\circ}$. followed by a second leg of approximately $3 \mathrm{~m}$. The seven values were administered in random order. After the presentation, the subject walked forward approximately $3 \mathrm{~m}$. reproduced the turn without aid. and walked another $3 \mathrm{~m}$ before being told to stop. The subject also made an estimate of the turn by adjusting a $28 \mathrm{-cm}$ pointer mounted on a horizonlally held board. The pointer was initially set straight ahead: the subject was to rotate it clockwise through an angle equal to the stimulus turn.
Triangle completion. The upper panel of Figure 1 depicts a general stimulus pathway consisting of two outbound legs ( $\mathrm{A}$ and $B)$, shown as solid lines, and the angle $(\alpha)$ between them; the subject was led by the experimenter over Legs $A$ and $B$ and then attempted to complete the third leg. $C$, shown as a dashed line: angle $\beta$ is the internal angle formed by the second and the third legs of the triangle. The lower panel of the figure depicts a typical subject response $\left(C^{\prime}\right)$. Note that the subject actually turned through an angle of $180^{\circ}-\alpha$ while being led and through an angle of $180^{\circ}-\beta^{\prime}$ while making the response.

Vertices of 27 triangles were marked on the floor of the work space with colored electrical tape. The triangles constituted a factorial combination of three lengths $(2,4$, or $6 \mathrm{~m})$ of Leg $A$. three lengths (2. 4, or $6 \mathrm{~m}$ ) of Leg B, and three values of angle $\alpha\left(60^{\circ}\right.$. 

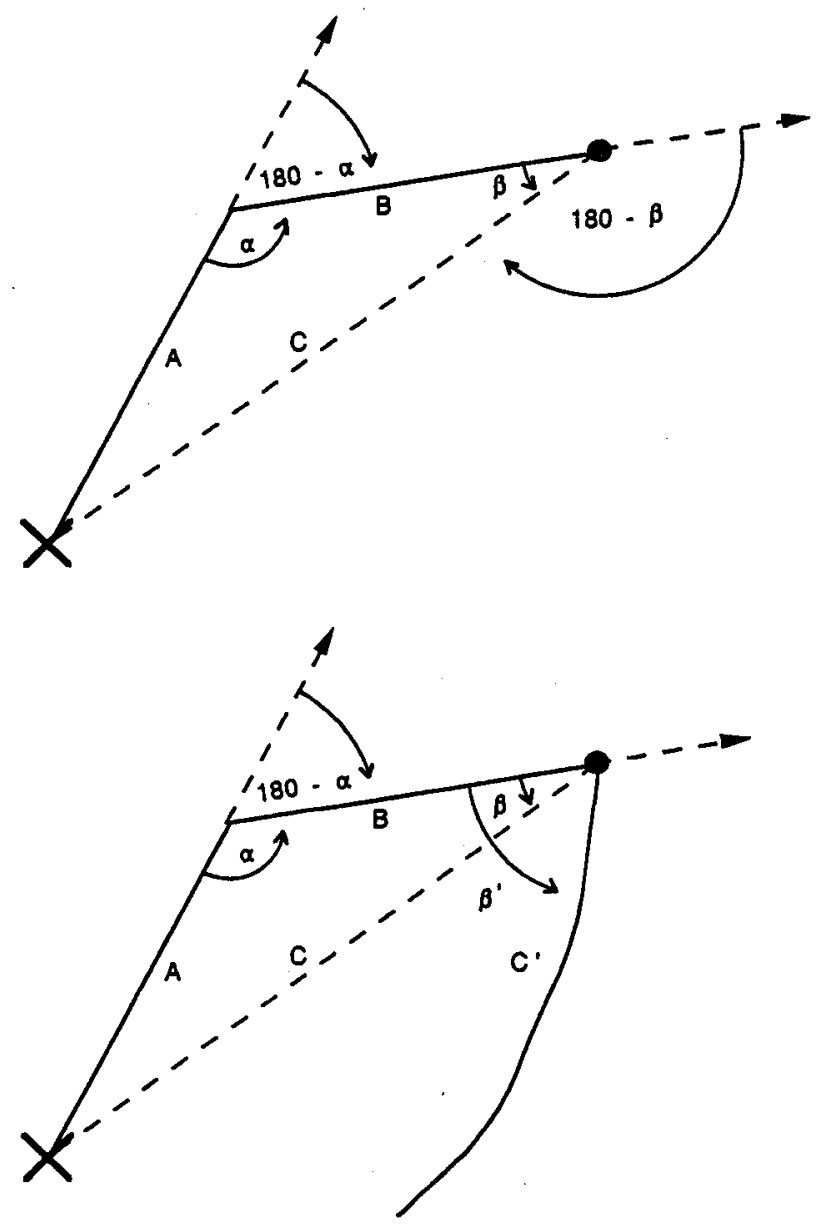

Figure 1. Depiction of a triangular path used in the pathway completion experiment (upper panel). (The subject was led along $\operatorname{Leg} A[2,4$, or $6 \mathrm{~m}]$, pivoted through an angle of $180^{\circ}-60^{\circ}, 90^{\circ}$, or $\left.120^{\circ}\right)$, and then led along Leg B $[2,4$, or $6 \mathrm{~m}]$. The correct turn toward home is given by $180^{\circ}-\beta$, and the length of the correct return leg is $C$. In the text we often refer to the internal angles $\alpha$ and $\beta$ of the triangle rather than the actual turn angles. The lower panel shows the same triangle with a representative response given by the solid curved line. The response is measured in terms of the walked distance $C^{\prime}$ and the internal angle $\beta^{\prime}$.)

$90^{\circ}$, or $120^{\circ}$ ). All triangles started at a common origin, and initial legs were aligned, as shown in the upper left panel of Figure 2. On each trial, the subject was passively led by an experimenter along the two outbound legs of the triangle. Specifically, the subject held onto the ends of handlebars and was led from the origin over the first leg, was stopped and pivoted through the turn in a clockwise direction, and was then led over the second leg. At the terminus of the second leg, the subject released the grip and attempted to return unaided to the origin, as depicted at the bottom of Figure 1. To eliminate feedback from one trial to the next, the subject was led from the stopping point through a circuitous route (lasting about $20 \mathrm{~s}$ ) back to the origin for the next trial. The order of the triangles was random, and the subject was informed that the lengths of the legs and the angle would vary randomly from trial to trial. A few congenitally blind subjects required familiarization with the shape of a triangle. This was done by having the subject feel a triangular block and then identify a triangle from among three shapes (square, triangle, and trapezoid).
Retrace-completion task. The subject was led through a pathway of two or three segments a total of six times. After each traversal, the subject either retraced the pathway or completed it by returning directly to its origin, and he or she was then given feedback. For pathway completion the assistant stood at the origin and called to the subject, thus providing feedback through auditory localization. For the retrace response, the subject received verbal feedback (e.g., "you turned too much;" "you went too far in retracing the first leg"). Three of the traversals were followed by retracing and three were followed by completion; there was no warning before the traversal as to which response would be required. This task was performed with four different pathway configurations; all six tests on a single configuration were completed before the next was introduced. The four configurations were used by Klatzky, Loomis, Golledge, Cicinelli, Doherty, and Pellegrino (1990), as part of a larger set. The turning points (i.e., segment ends) were on the circumference of a circle $6 \mathrm{~m}$ in diameter (cf. $10 \mathrm{~m}$ and $3 \mathrm{~m}$ in the earlier study). The configurations were selected to vary in difficulty, and the same identifying numbers used previously are used here (5 and 7 were two-segment pathways, with 7 producing more errors, and 9 and 11 were three-segment pathways, with 11 producing more errors; three of the pathways are shown in the results.) The order of the pathways was counterbalanced over subjects, and within each subject, the order of responses was pseudorandom, with these restrictions: Half the pathways were tested first with retracing and half were tested first with completion, and the same response type occurred no more than twice in succession with a given pathway.

\section{Results: Simple Locomotion Tasks}

The measure of walked distance was obtained by summing the distance between successive points on the trajectory (cumulative path length). The measure of turn was obtained from the first $2 \mathrm{~m}$ of the first leg and the last $2 \mathrm{~m}$ of the second leg. A regression line was fit to each segment to determine heading in the work space, and turn was then measured as the change in heading. (Turn was always to the right.) These tasks indicated no differences among groups in the ability to perform simple reproductions of turns and linear segments.

Distance reproduction and estimation. Errors of distance reproduction changed from overestimation for the $2-\mathrm{m}$ distance $(26 \mathrm{~cm})$ to increasing underestimation with longer paths $(-27,-40,-144$, and $-102 \mathrm{~cm}$ for distances of $4,6,8$, and $10 \mathrm{~m}$, respectively). This same trend was observed in our earlier study. An analysis of variance (ANOVA) on group and distance showed an effect only of distance, $F(4,132)=5.66, p<.001$. Absolute error increased over the five distances (errors were 42, 66, 109, 161 , and $249 \mathrm{~cm}$ ), and again, the ANOVA showed only a distance effect, $F(4,132)=15.94, p<.001$.

Signed errors of distance estimation showed trends similar to those of reproduction (errors over the five distances were $32,12,31,-88$, and $-72 \mathrm{~cm}$ ). The ANOVA on group and distance showed only an effect of distance, $F(4,136)$ $=4.14, p<.01$ (note that the difference in degrees of freedom from earlier reflects the loss of one reproduction observation due to camera error). Similarly, absolute errors 

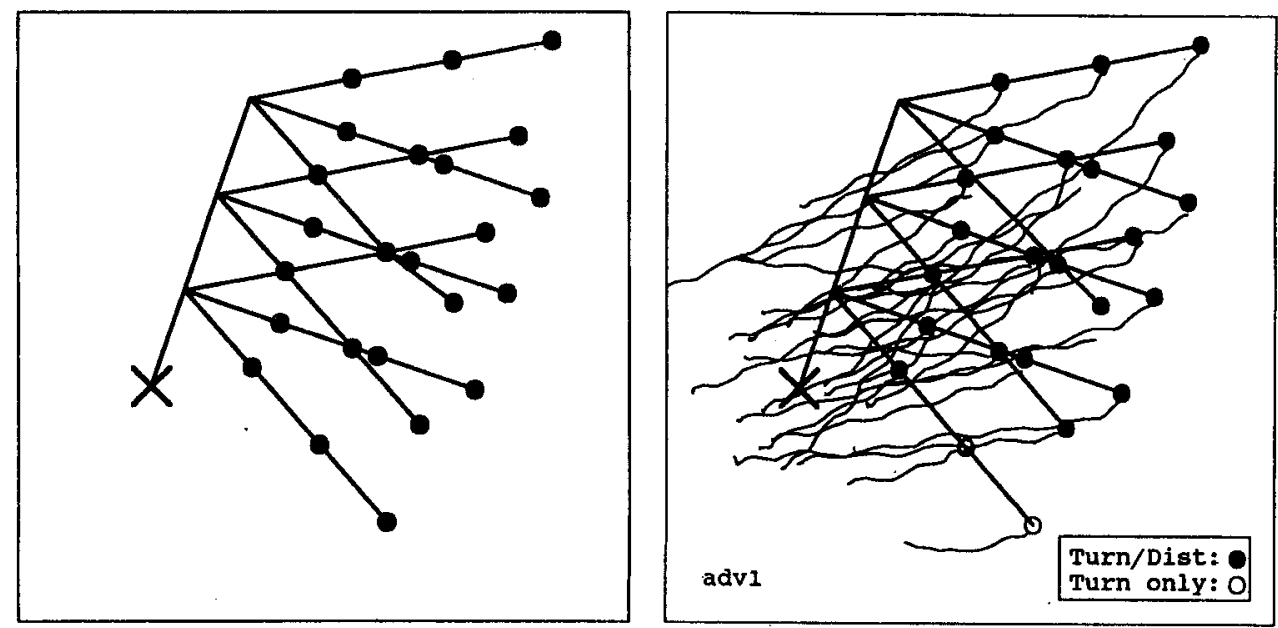

Figure 2. The triangles used in pathway completion (left panel, also see Figure 1). (The 27 triangles were created by crossing three lengths of the first leg $[2,4$, or $6 \mathrm{~m}]$, three lengths of the second leg $[2,4$, or 6$]$, and three values of the angle between them $\left[60^{\circ}, 90^{\circ}\right.$, or $\left.120^{\circ}\right]$. The origin of locomotion is indicated by $\mathrm{X}$. The legs over which the subjects were guided are shown by the solid lines, and the drop-off points are given by the solid symbols. The right panel shows the computer-measured responses of an adventitiously blind subject [adv1] performing triangle completion. On some trials the full trajectory could not be measured; on these trials, indicated by the open symbol at the drop-off point [Turn only], only the turn toward the origin was computed. All other trials for which both turn and distance were computed [Turn/Dist] are shown by the solid symbols.)

increased with distance, $F(4,136)=8.50, p<.0001$, with no effects involving group (errors were 54, 118, 158, 191, and $261 \mathrm{~cm}$.)

Turn reproduction and estimation. Signed turn reproduction again showed an error pattern changing from overto underestimation (over the seven angles of $60^{\circ}, 90^{\circ}$, $120^{\circ}, 180^{\circ}, 240^{\circ}, 270^{\circ}$, and $300^{\circ}$, errors in degrees were $21,9,21,-1,-4,-9$, and -30 , respectively). An ANOVA on group and turn showed only a main effect of turn, $F(6$, $198)=9.40, p<.001$. Absolute turn errors showed an increasing trend over the turn values (errors in degrees were $24,16,29,18,33,35$, and 38). The ANOVA on absolute errors with group and turn showed only a main effect of turn, $F(6,198)=3.19, p<.01$. Both the signed and absolute error functions were nonmonotonic, showing relatively greater accuracy when the turn was a multiple of $90^{\circ}$. This tendency has been noted by Klatzky, Loomis, Golledge, Cicinelli, et al. (1990).

The signed errors of turn estimation showed underestimation for all angles, increasingly so over the angular values (errors in degrees were $-9,-15,-8,-21,-27,-18$, and -34 over the seven angles). The ANOVA on group and angular value showed only a main effect of angle, $F(6$, $204)=2.83, p<.05$. Similarly, absolute errors increased with angle, $F(6,204)=8.20, p<.0001$ (errors in degrees were $24,20,28,25,45,42$, and 47 ).

\section{Results: Complex Locomotion Tasks}

Triangle completion. Distance was measured the same way as in the simple locomotion tasks (cumulative path length). To measure the turn back toward the origin, the data within $50 \mathrm{~cm}$ of the turn point (terminus of the second leg) were discarded and the next $2 \mathrm{~m}$ of the subject's trajectory were fit by regression to obtain heading in the work space. The turn was calculated as the difference between this heading and the heading of the second leg.

The left panel of Figure 2 shows the 27 outbound pathways formed by the factorial combination of three lengths for each of two legs and three turn values and their layout in the work space. The right panel of Figure 2 and Figures 3,4 , and 5 show the corresponding trajectories for all 37 subjects. ${ }^{2}$ Some of the trajectories could not be properly measured over their entirety because the subject walked out of the field of view of either camera or, rarely, because of problems with equipment. These trajectories were not used for distance data but contributed to turn data. The valid trajectories contributed to four measures: signed error in the subject's walked distance, signed error in the subject's turn toward the origin, and the corresponding absolute errors. The mean values for these measures are shown by group in Table 2 .

Figure 6 plots mean turn and mean distance as functions of the respective correct values by group. (Data are pooled over valid trajectories for each configuration.) Clearly, subjects' responses indicate sensitivity to the manipulated parameters of the pathways; the mean responses are well fit by linear functions of the correct values $\left(r^{2}\right.$ for turn $=.85$.

\footnotetext{
${ }^{2}$ Readers interested in obtaining computer files with the entire set of trajectories for triangle completion should contact Jack $M$ Loomis.
} 
.83 , and .93 for congenitally blind, adventitiously blind, and sighted; $r^{2}$ for distance $=.83, .88$, and .92 ). The overall trend, however, is for compression of the range of responses relative to the correct values. It is also notable that the functions for the three groups were quite similar. Differences among groups were analyzed by computing a linear regression for each subject and then comparing the slopes and $r^{2}$ (degree of linear fit) for turn and distance. None of these differences was significant.

Additional regression analyses focused on subjects' sensitivity to the parameters of the triangles-length of first leg (A), length of second leg (B), and angle between legs $(\alpha)$. Multiple linear regression was used to predict subjects' turn and distance responses. In actuality, the correct response was not a strictly linear function of $\mathrm{A}, \mathrm{B}$, and $\alpha$, but a linear model predicted high percentages of the variances in correct turn and distance (90\% and 94\%, respectively). This can be seen in the regression parameters for an "ideal" subject, who responded correctly each time, in rows labeled Ideal in Table 3.

Group means on the 27 configurations were modeled with linear regression, providing standardized weights for
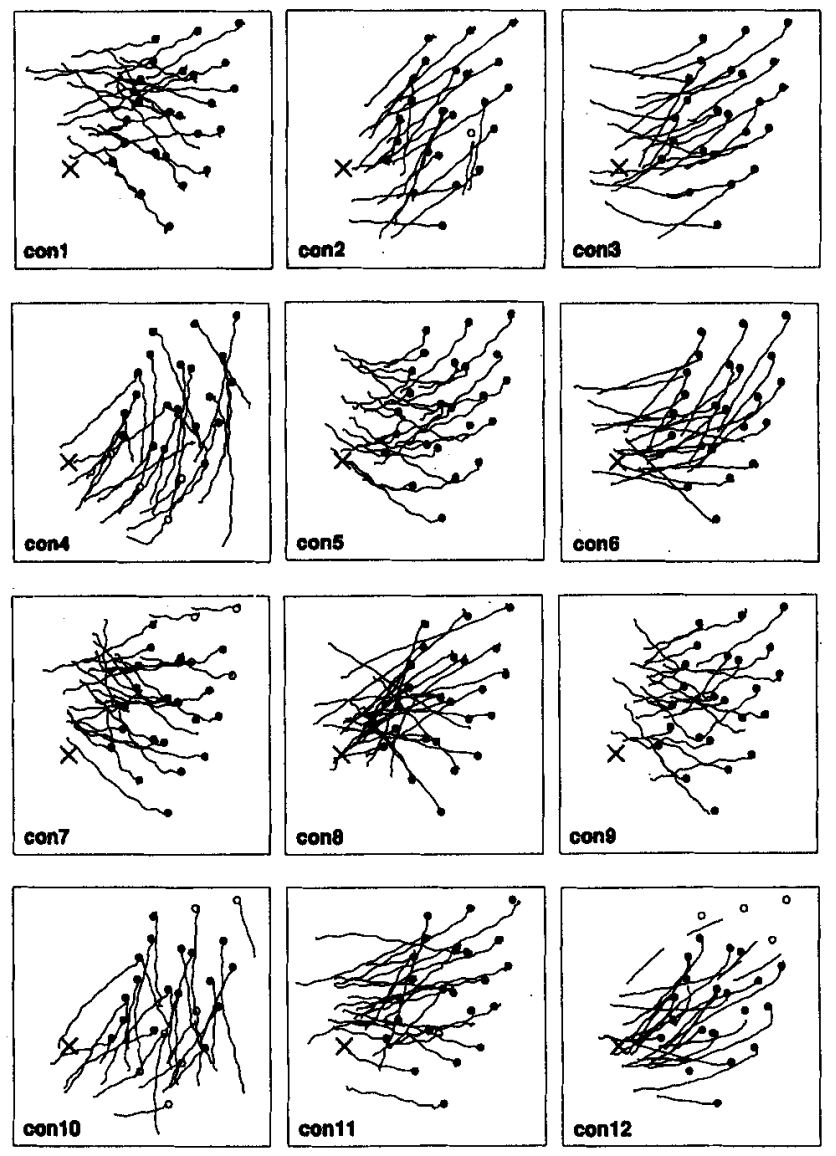

Figure 3. The responses of the 12 congenitally blind (con) subjects in the triangle completion task. (The origin of motion is indicated by $X$. The legs over which the subjects were guided are shown by the solid lines, and the drop-off points are given by the solid symbols.)
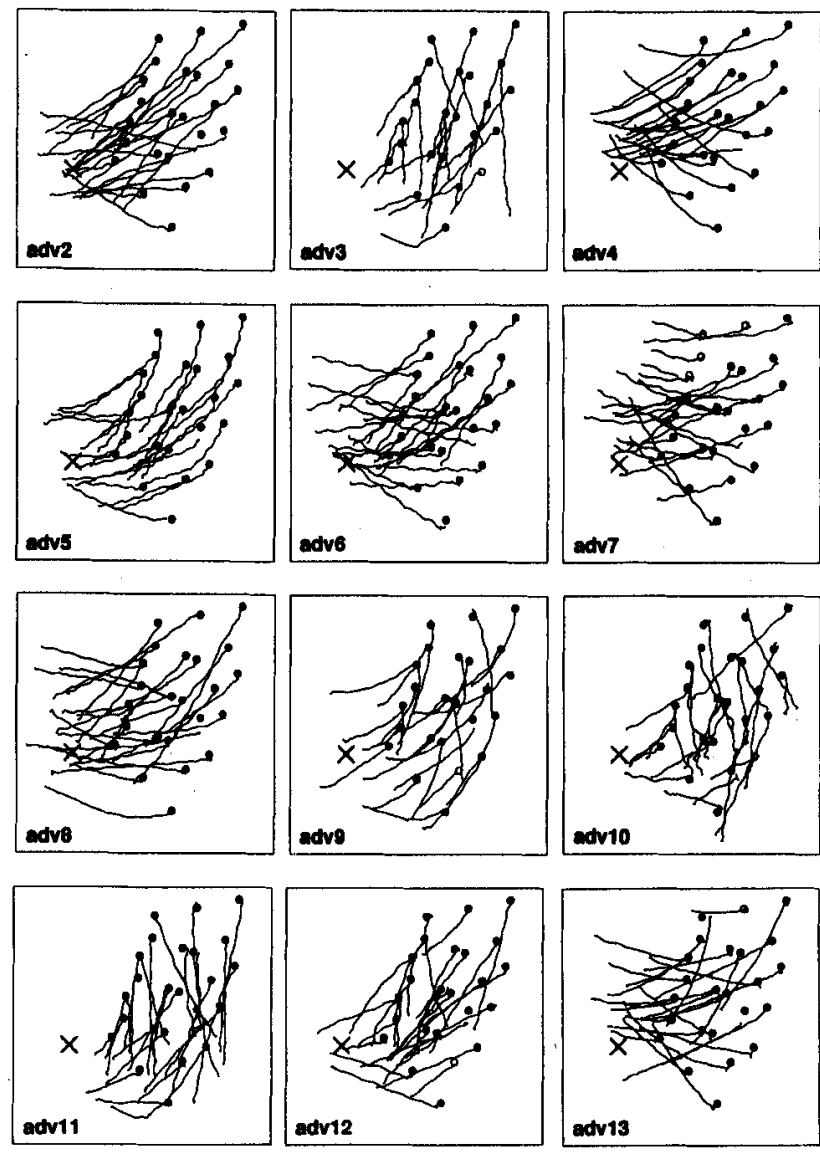

Figure 4. The responses of the 12 adventitiously blind (adv) subjects in the triangle completion task. (The origin of motion is indicated by $X$. The legs over which the subjects were guided are shown by the solid lines, and the drop-off points are given by the solid symbols.)

$\mathrm{A}, \mathrm{B}$, and $\alpha$ that can be compared with the "ideal" subject. Note that this analysis is insensitive to constant additive error (e.g., always turning $20^{\circ}$ too much or walking $1 \mathrm{~m}$ too little) or errors of scale (e.g., overturning by a constant proportion of correct turn). Table 3 presents the regression weights by group. All weights were significantly different from zero at the .01 level and were signed correctly (i.e., in the same way as the ideal subject). Hence, the average subject in each group was sensitive to the manipulated variables of the pathway.

Retrace-completion task: Completion. Distance and turn responses for completion trials in the completion or retrace task were measured the same way they were in triangle completion. We have previously reported completion performance on the four paths used here by a sighted blindfolded population (Klatzky, Loomis, Golledge, Cicinelli, et al., 1990). The particular configurations were (except for a change of scale) a subset of the original set, chosen because they produced relatively high or low error. The measured variables were signed and absolute error in the turn toward the origin and the walked distance. Errors generally decreased with repetition, but it is not clear how 

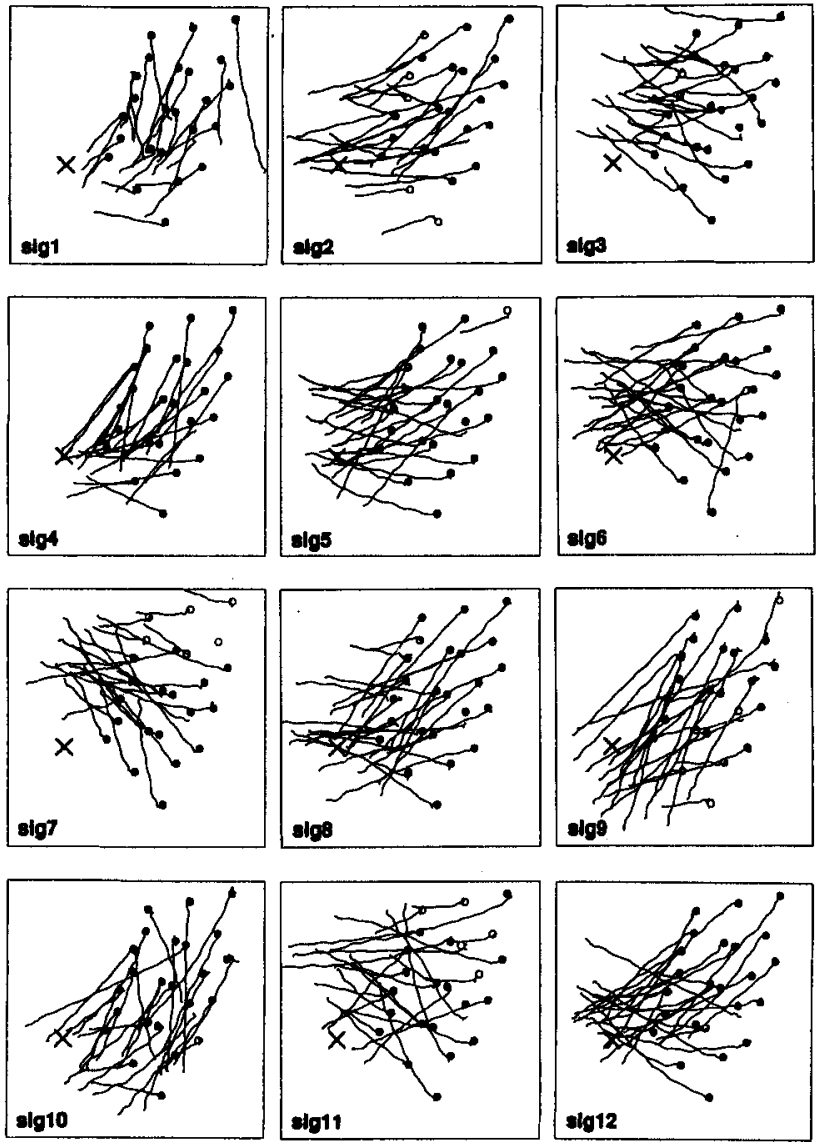

Figure 5. The responses of the 12 sighted (sig) subjects in the triangle completion task. (The origin of motion is indicated by $X$. The legs over which the subjects were guided are shown by the solid lines, and the drop-off points are given by the solid symbols.)

to interpret this result. Either subjects were learning the configuration and improving their return responses or they were simply using feedback about the correct turn and distance to improve the accuracy of the response without even attending to the configuration. In light of this ambiguity of the later trials in the completion task, our analysis focuses only on the first trial; mean signed and absolute error for turn and distance are presented for this condition by group and configuration in Table 4.

With one exception, ANOVAs on the error measures, with group, repetition, and configuration, showed no effects involving group. The exception was a significant Group $\times$ Configuration effect on signed distance error, $F(6,90)=2.76, p<.025$. (The means for this interaction

Table 2

Errors on the Triangle-Completion Task by Group

\begin{tabular}{|c|c|c|c|c|c|c|}
\hline \multirow[b]{2}{*}{ Error } & \multicolumn{3}{|c|}{ Turn error (degrees) } & \multicolumn{3}{|c|}{ Distance error $(\mathrm{cm})$} \\
\hline & Con & Adv & Sighted & Con & Adv & Sighted \\
\hline $\begin{array}{l}\text { Absolute } \\
\text { Signed }\end{array}$ & $\begin{array}{r}24 \\
-16 \\
\end{array}$ & $\begin{array}{r}22 \\
3 \\
\end{array}$ & $\begin{array}{r}24 \\
-4 \\
\end{array}$ & $\begin{array}{r}137 \\
-83 \\
\end{array}$ & $\begin{array}{r}107 \\
-61 \\
\end{array}$ & $\begin{array}{r}168 \\
-161 \\
\end{array}$ \\
\hline
\end{tabular}

Note. Con $=$ congenitally blind; $\mathrm{Adv}=$ adventitiously blind. show the same trends as the first-trial data in Table 4 and are not reported separately). Generally, all groups tended to undershoot in distance for Configurations 5, 9, and 11 and to overshoot for Configuration 7 . The same general pattern was found for these configurations in Klatzky, Loomis, Golledge, Cicinelli, et al. (1990), suggesting that the configurations produce systematic distortions that are shared among the groups. The amount of over- and undershooting varied across groups, however, yielding the interaction. In particular, the sighted appeared to be more consistently affected by the nature of the configuration than either of the blind groups. The $F$ values for the other significant effects on completion performance are shown in Table 5.

Retrace-completion task: Retrace. Figure 7 gives a representative sample of retrace performance by individual subjects. We analyzed each subject's performance on the entire trajectory by computing the distance of the subject's endpoint from the correct location. An ANOVA on group, repetition, and configuration showed that error decreased slightly with feedback over repetitions, $F(2,68)=3.58, p$ $<.05$. The errors were 270, 247, and $243 \mathrm{~cm}$ for Repetitions 1, 2, and 3, respectively. There was also a main effect of configuration. Errors were $182 \mathrm{~cm}$ and $221 \mathrm{~cm}$ on the two-segment pathways (5 and 7), $249 \mathrm{~cm}$ on the open three-segment configuration (9) and 363 on the threesegment configuration with a crossover (11). There was no effect of visual status $(F<1)$. Notice, however, that one of the congenitally blind subjects (Con 1) turned in the wrong direction three out of six times after retracing the first leg (in Configurations 5 and 9).

We also analyzed retrace performance for each segment. One of the experimenters estimated the pivot point for each turn in the plotted trajectory. For each segment, error was determined as the distance between the subject's pivot point (or on the last leg, the subject's stopping point) and the correct endpoint of that segment. On the first segment, subjects had merely to turn $180^{\circ}$ and repeat the distance they had just walked. An ANOVA performed on the Segment-1 data with configuration, group, and repetition showed that even on the first leg, there was an effect of configuration (mean errors for Pathways 5, 7, 9, and 11 were $84,108,85$, and $168 \mathrm{~cm}$, respectively). No other effects were significant, including group $(F<1)$.

The final analysis examined the effect of segment number for the three-segment pathways. It also included group, configuration, and repetition as factors. There were effects of configuration, $F(1,34)=16.73, p<.001$, segment number, $F(2,68)=109.22, p<.01$, and interactions between segment and configuration, $F(2,68)=9.19, p<$ .001 , and between segment and repetition, $F(4,136)=$ $3.37, p<.05$. Again, there was no group effect $(F<1)$. The pattern of these effects is shown in Table 6. Subjects drifted further and further from the correct pathway with each leg, particularly for the more complex pathway. The effect of repetition with feedback was greater for the last leg of the pathway than for earlier legs. This is likely to reflect greater attention by the experimenters to the end of the trajectory, which would be reflected in their feedback. 
SIG
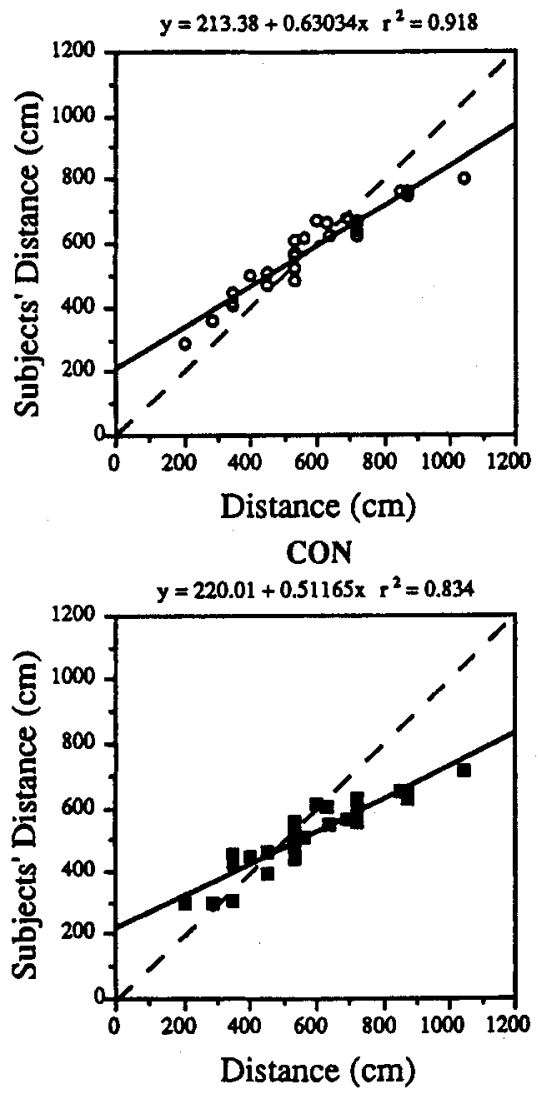

ADV

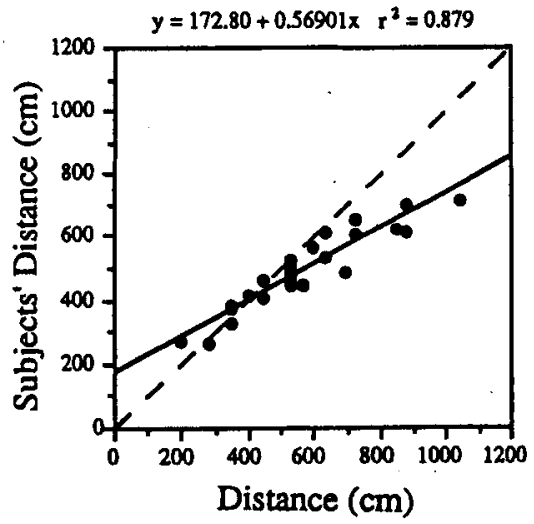

SIG
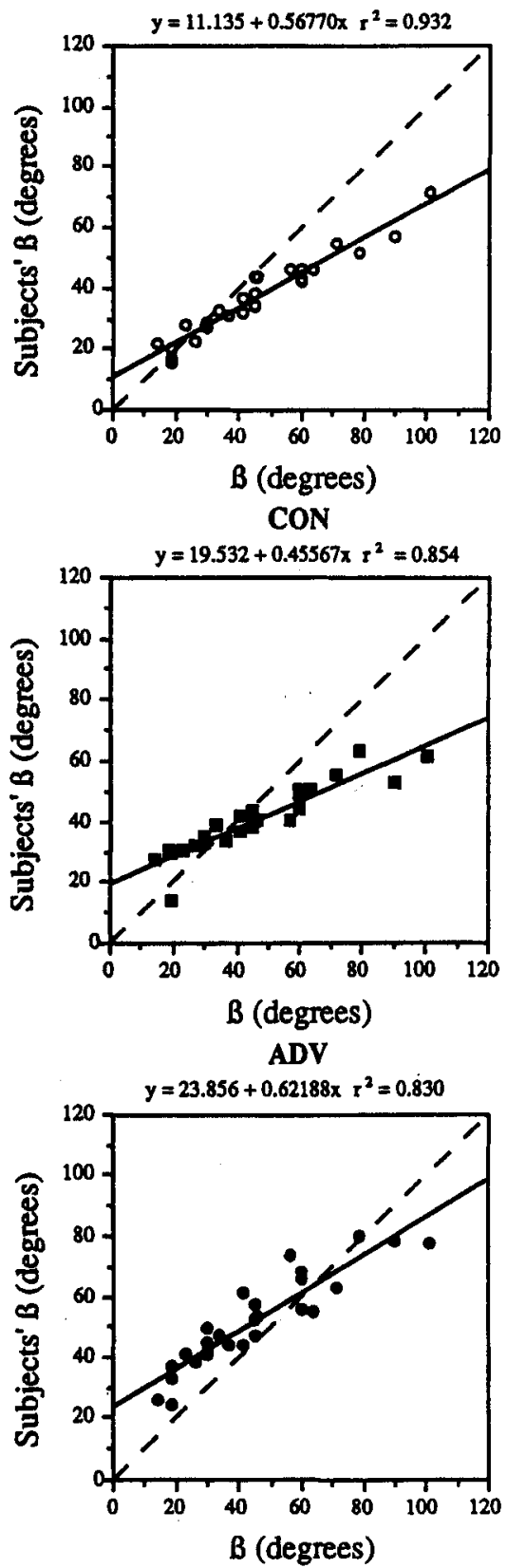

Figure 6. Results of simple linear regression analyses for triangle completion. (The left panels show, for each group, the walked distance against the correct distance of the return leg for the 27 triangles, averaging over the individuals within that group. The right panels show the same for the turn $[\beta]$ data. In general, mean walked distance and mean turn response exhibit regression to the mean. The regression equations are given above each panel. SIG $=$ sighted; CON = congenitally blind; $\mathrm{ADV}=$ adventitiously blind.)

Latencies for the subject to begin retracing or completion were also measured. Figure 8 shows the latencies by configuration (left panel) and by trial (right panel). An ANOVA on latency with response type (completion or retrace), configuration, group, and repetition revealed a main effect of configuration, $F(3,102)=3.49, p<.05$, and in- teractions between configuration and task, $F(3,102)=$ $2.85, p<.05$, and between task and repetition, $F(2,68)=$ $3.23, p<.05$. The latter arose because initiation of the completion task became faster over repetitions, but retracing did not. More important, there was a substantial difference among the configurations in the time to initiate com- 
Table 3

Results of Multiple Linear Regression on Turn and Distance for an Ideal Subject and for the Group Means

\begin{tabular}{lrrrrr}
\hline & \multicolumn{5}{c}{ Weight } \\
\cline { 3 - 5 } Group & Intercept $^{\mathrm{a}}$ & $\mathrm{A}$ & $\mathrm{B}$ & Alpha & $R^{2}$ \\
\hline \multicolumn{5}{c}{ Turn } \\
Ideal & 90.0 & -.54 & .54 & .56 & .90 \\
Con & 125.1 & -.57 & .49 & .43 & .74 \\
Adv & 109.7 & -.63 & .36 & .52 & .80 \\
Sighted & 126.3 & -.63 & .54 & .42 & .87 \\
\hline \multicolumn{5}{c}{ Distance } \\
Ideal & -353.5 & .57 & .57 & .54 & .94 \\
Con & 77.0 & .55 & .74 & .23 & .90 \\
Adv & -3.6 & .50 & .68 & .38 & .84 \\
Sighted & -3.2 & .54 & .65 & .44 & .87 \\
\hline
\end{tabular}

Note. Con $=$ congenitally blind; $\mathrm{Adv}=$ adventitiously blind.

a Measured in degrees for turn and in centimeters for distance.

pletion but not in the time to initiate retracing. The threeleg patterns showed higher completion latencies than the two-leg patterns, with Configuration 11 being particularly slow.

This finding led us to reanalyze the corresponding latency data in the completion task of Klatzky, Loomis, Golledge, Cicinelli, et al. (1990), which used the same pathways as part of a set of 12 configurations, at two different scales (two repetitions, but without feedback). Averaged over scale, the path completion latencies were $2.8 \mathrm{~s}$, $2.6 \mathrm{~s}, 2.8 \mathrm{~s}$, and $3.3 \mathrm{~s}$, for Configurations $5,7,9$, and 11 , respectively in that study, replicating the pattern we found but being faster overall. The complete configuration set included four configurations at each number of legs-one, two, or three. An ANOVA on latencies for those data, averaged over scale (which preliminary analyses showed to have no effect), with number of legs and configuration (nested within legs), showed only an effect of legs, $F(2$, 22 ) $=3.92, p<.05$ (latencies were $2.7,2.8$, and $3.1 \mathrm{~s}$ for 1,2 , and 3 legs, respectively). Thus, the latency to begin pathway completion seemed to increase as pathway complexity increased.

\section{Discussion}

A number of our results show that simple locomotion tasks were performed reasonably well. We have previously reported assessments on most of these same tasks with the range of stimulus values used here (Klatzky, Loomis, Golledge, Cicinelli, et al., 1990). The present results generally agree with the previous ones, although there is a tendency for the errors to be somewhat larger in this population. The maximum signed error in the distance reproduction task, about $1 \mathrm{~m}$ for a 10-m distance, was approximately the size of a footstep, as in our earlier data set. However, the maximum absolute error in the same task, 2.5 $\mathrm{m}$ for the $10-\mathrm{m}$ distance, was almost twice as large as the corresponding value in our previous study. The absolute turn error was also substantially greater than our previous results (e.g., a maximum of $38^{\circ}$ for absolute error in reproduction here vs. approximately $25^{\circ}$ in our previous study). Furthermore, the present signed error for turns compressed the response range more than we obtained previously, showing a greater tendency to underestimate large angles. These differences in turn data are quite likely the result of procedural differences, for the turn task was quite different from that used earlier-turning while walking in the present study as opposed to rotation within a circular hoop in the previous study.

The data from the triangle completion task show clearly that subjects, on average, were sensitive to the manipulations of leg length and turn angle. Their turn and distance responses, averaged over subjects, increased more or less linearly with the correct values (i.e., what they should have responded); there was overshooting of short distances and undershooting of long distances. Multiple regression analyses on the means over subjects, using the 27 pathways as observations, showed that a large portion of the variance in turn and distance responses was accounted for by the parametric pathway values (leg lengths and turn angle).

Although subjects were sensitive to the manipulations of leg length and turn angle, the performance data indicate that triangle completion is quite a difficult task, even over the short distances used here. Not only were there significant signed errors for the average of all subjects (Table 3 ) but also no single subject came close to exhibiting negligible errors over the 27 triangles (Figures 2-5). It appears that even for the short paths over which subjects were passively

Table 4

Mean Signed and Absolute Turn Errors (in Degrees) and Distance Errors (in Centimeters) by Group and Configuration on First Trial of Pathway Completion

\begin{tabular}{|c|c|c|c|}
\hline \multirow[b]{2}{*}{ Configuration } & \multicolumn{3}{|c|}{ Group } \\
\hline & Congenital & Adventitious & Sighted \\
\hline \multicolumn{4}{|c|}{ Signed turn error } \\
\hline 5 & -0.9 & -4.8 & 4.6 \\
\hline 7 & 14.1 & 3.1 & 28.3 \\
\hline 9 & -3.9 & -6.4 & -0.6 \\
\hline 11 & -57.3 & -29.6 & 11.9 \\
\hline \multicolumn{4}{|c|}{ Absolute turn error } \\
\hline 5 & 13.9 & 17.5 & 18.3 \\
\hline 7 & 21.6 & 34.6 & 29.4 \\
\hline 9 & 25.2 & 22.1 & 12.6 \\
\hline 11 & 91.6 & 84.9 & 117.1 \\
\hline \multicolumn{4}{|c|}{ Signed distance error } \\
\hline 5 & -34 & -23 & -2 \\
\hline 7 & 75 & 9 & 55 \\
\hline 9 & -106 & -28 & -81 \\
\hline 11 & -157 & -33 & -239 \\
\hline \multicolumn{4}{|c|}{ Absolute distance error } \\
\hline 5 & 78 & 71 & 72 \\
\hline 7 & 96 & 81 & 108 \\
\hline 9 & 151 & 79 & 134 \\
\hline 11 & 168 & 165 & 245 \\
\hline
\end{tabular}


Table 5

$F$ Values for Significant Effects on Pathway Completion Performance Involving Configuration (Con) and Repetition (Rep)

\begin{tabular}{lccc}
\hline \multicolumn{1}{c}{ Measure } & Con & Rep & Con $\times$ Rep \\
\hline Signed turn & 13.28 & $n s$ & $n s$ \\
Absolute turn & 35.78 & 14.87 & 9.04 \\
Signed distance & 20.40 & 5.81 & 3.22 \\
Absolute distance & 12.07 & 20.46 & 3.46 \\
$\quad$ & & & \\
$\quad d f \mathrm{~s}$ & 3,90 & 2,60 & 6,180 \\
\hline
\end{tabular}

Note. All ps $<.01$.

guided here, the proprioceptive and vestibular cues were inadequate for accurate path integration. The systematic errors in this task are the focus of a model devised by Fujita, Klatzky, Loomis, and Golledge (1993; see also Klatzky, Loomis, Golledge, Fujita, \& Pellegrino, 1990).

The errors on completion trials of the completion-retrace task were greatest with Configuration 11, in which the third segment crossed back over the first. This result, along with the very poor showing of the same configuration in the earlier study (Klatzky, Loomis, Golledge, Cicinelli, et al., 1990), suggests that the difficulty of a configuration is determined by more than just its total length and number of legs. The difficulty of Configuration 11 was also evident in the large retracing errors relative to those of the other configurations.

Although our tasks represent a fairly wide range of difficulty and sample from those that might be performed on the basis of route and survey knowledge, Experiment 1 generally failed to show any systematic group differences in performance as a function of visual experience. We attempted in the completion-retrace task to have the subject keep track of multiple locations in space, because he or she was not informed as to which response was required until after the path had been encoded. However, it could be argued that even for the most difficult pathway (11), the subject needed to represent only the origin and two other pivot points to perform either the retrace or completion response. The task of Rieser et al. (1986) appears to demand
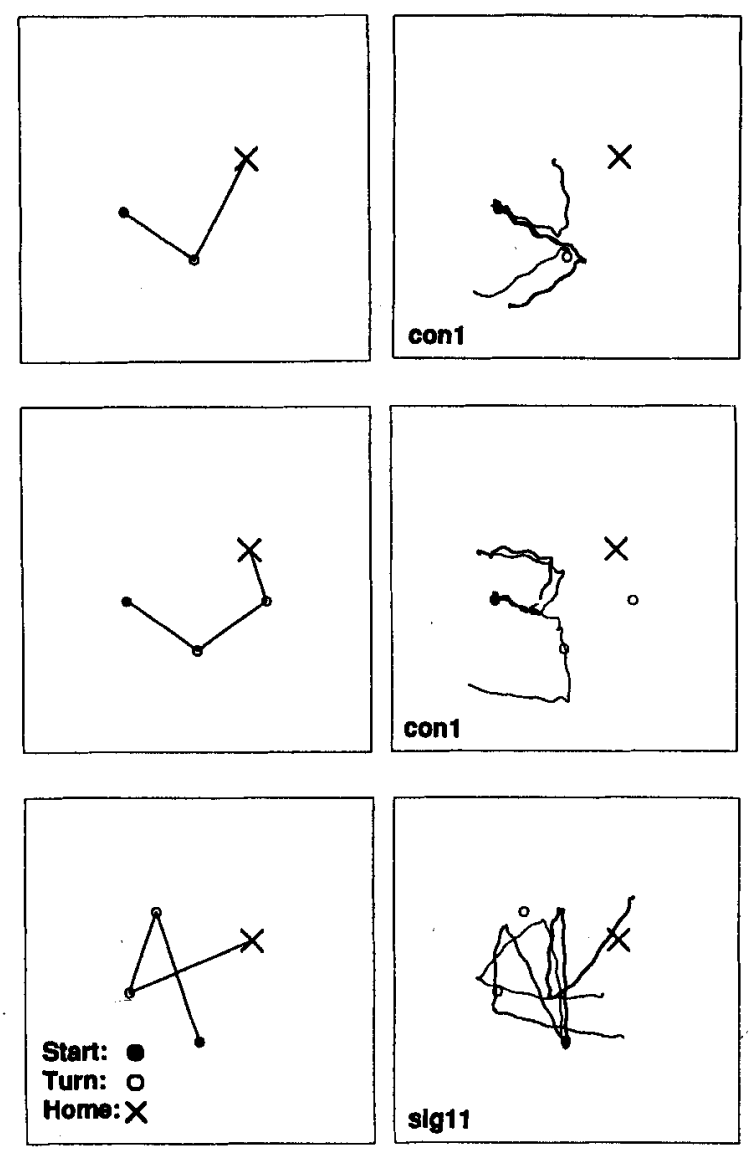
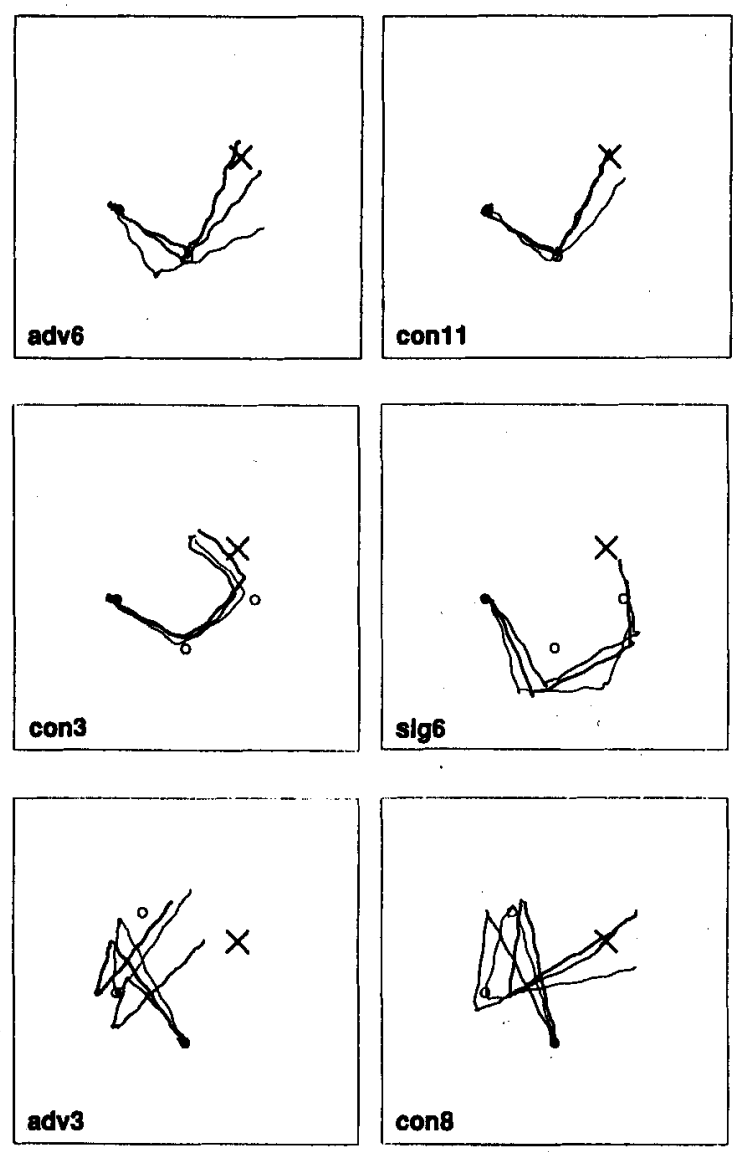

Figure 7. Representative results of the retracing task. (The three left panels represent three of the four configurations used in the task. The origin of the retrace [Start] is given by the solid symbol, the pivot points [Turn] are given by the open symbols, and the terminal point [Home] is given by $X$. The remaining panels show the walking trajectories of selected congenitally blind [con], adventitiously blind [adv], sighted [sig] subjects. In each panel, the three attempts at retracing are given in sequence by lines of increasing thickness.) 
Table 6

Error (in Centimeters) in Retracing by Segment Number for Each Configuration and Repetition

\begin{tabular}{lrcc}
\hline & \multicolumn{3}{c}{ Segment } \\
\cline { 2 - 4 } Task condition & 1 & 2 & 3 \\
\hline Configuration & & & \\
9 & 85 & 186 & 249 \\
11 & 168 & 191 & 363 \\
Repetition & & & \\
1 & 119 & 195 & 334 \\
2 & 130 & 186 & 303 \\
3 & 129 & 184 & 281 \\
\hline
\end{tabular}

more of memory and spatial inference, for the subject must learn the locations of several objects and update their position during both real and imagined locomotion. Given the substantial differences in performance between early blind and sighted individuals that these researchers reported, we decided to repeat the task with a subset of the current blind subjects and matched controls. Failure to obtain group differences in this case would call into question the hypothesis that the early blind are at a disadvantage in navigation tasks requiring spatial inference.

\section{Experiment 2}

\section{Method}

Subjects. The sighted subjects are described in Table 7. The congenitally blind subjects were among those who had participated in the main experiment and are identified in the results section by the labels given in Table 1 . All were blindfolded throughout the experiment. Each was paid for participation.

Procedure. The procedure followed closely that of Rieser et al. (1986), although there were some minor differences. Six objects were placed on stools within a large room in the configuration shown in Figure 9. The objects were a phone receiver, eye- glasses, wooden spoon, ice tray, baseball, and mug. A seventh stool served as the home position, as marked in figure 9. Resting on this stool was a pointer apparatus fashioned after that used by Rieser et al. It consisted of a metal pointer that rotated within a horizontal plane; it was mounted above a protractor and wired to a stopwatch. The apparatus was used to collect both response times and angular responses. The experiment lasted about $1.5 \mathrm{hr}$ and comprised the following four phases.

Training in the use of the pointer was first. This was accomplished by having the subject point toward audible clicks. On each trial, one experimenter assumed a position in the work space and produced a click with a noisemaker, while the other started the stopwatch. The subject, who was standing behind the pointer and grasping it with the preferred hand, rapidly rotated the pointer toward the direction of the sound and then pushed downward on its tip, which stopped the stopwatch. The pointer was then reset to straight ahead before the next trial. The subject was first familiarized with the pointer until responses could be produced within $2 \mathrm{~s}$ with less than $15^{\circ}$ of error. Subjects then commenced 25 data-collection trials in which they were told to respond as quickly and accurately as possible. The click origin was varied within a semicircle in front of the subject at a 3-6-m radius.

For the remaining phases of the experiment, the subject wore headphones connected to a receiver (Model Telex AAR-1); the headphones received a signal from an omnidirectional microphone and transmitter (Model Telex TW-6 FM Wireless Microphone) placed outside of the work space. With equal input to both ears, the result was that all sounds, including the experimenter's voice, appeared not to have any definite location in the subject's auditory space. (At the outset, the volume of the receiver was adjusted for each subject to insure that localization of even loud sounds was impossible.) This effective means of preventing orientation by auditory cues was recommended to us by Rieser (January 1990), who conceived its use in the study by Rieser et al. (1986).

Learning the object layout was the second phase. First, the set of object names was recited in left-to-right order to the subject, who repeated it. This was done until the names had been memorized (about 3 to 5 times). Next, the subject was carefully led to a position just behind the home stool and asked to align his or her

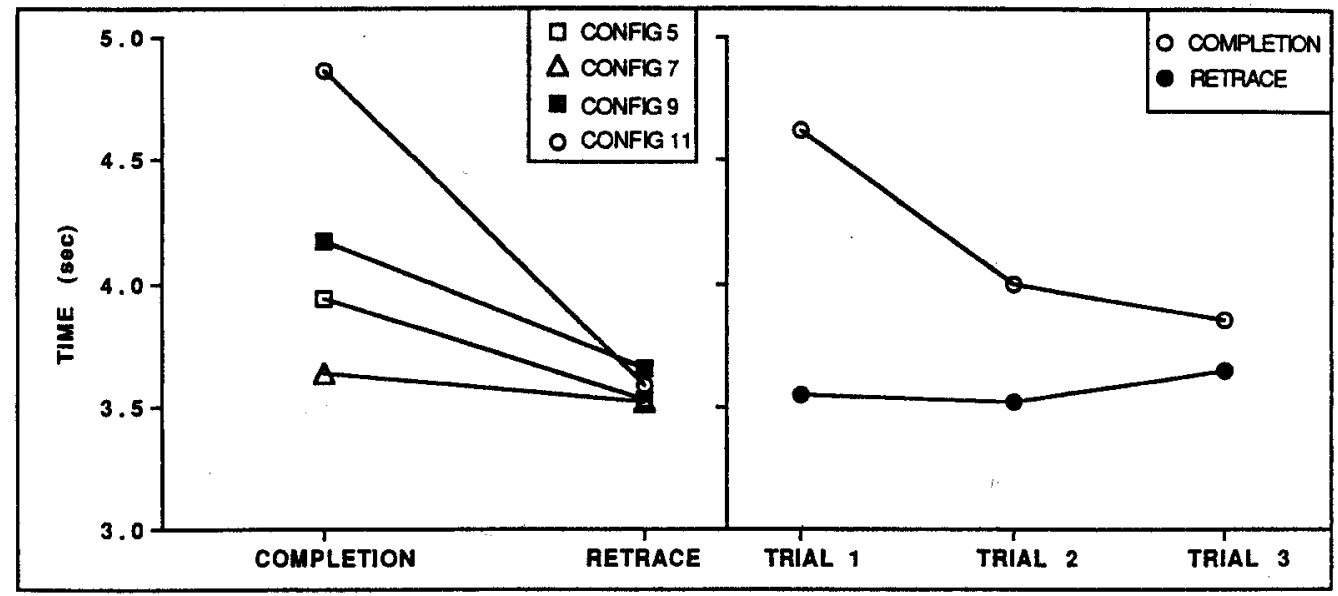

Figure 8. Summary of the latency data in the retrace-completion task. (The left panel gives the mean latencies to begin the retrace and completion responses, as a function of configuration [CONFIG]. The right panel shows how latency, averaged over configurations and subjects, varied with trial and task.) 
Table 7

Subject Characteristics in Rieser, Guth, and Hill (1986) Task

\begin{tabular}{clcc}
\hline Number & Age & Gender & Education \\
\hline 13 & 39 & M & BA \\
14 & 21 & M & BA \\
15 & 44 & M & BA \\
16 & 41 & F & AA \\
17 & 19 & M & HS \\
\hline
\end{tabular}

Note. All subjects were sighted. $\mathrm{BA}=$ Bachelor of Arts; $\mathrm{AA}=$ Associate of Arts; HS = high school.

body with its edge. The stool was removed, and he or she was then led directly to the object farthest to the left and back, aligned with the replaced home stool as before, and then asked to point to the object with a raised arm. This was repeated until pointing was reasonably accurate; usually only one or two trials were needed. The subject was then led to the next object (in a rightward direction as seen from the origin) and then back to the home position and asked to point to the first and second objects. This procedure was repeated, each time requiring the subject to point to all previous objects as well as the new one introduced, until the entire set had been presented. The entire procedure was then repeated a second time.

Baseline test and reminder was the third phase. The subject was asked to use the pointer to point to each object as quickly and accurately as possible. The objects were tested in random order, with the pointer reset to straight ahead between responses. Pointing began with the experimenter's naming the object, which coincided with starting the stopwatch. Depression of the adjusted pointer by the subject stopped the stopwatch. After each object had been tested once, the test was replicated in a new order. The baseline test was followed by a reminder phase, which was identical with one repetition of the learning procedure.

The fourth phase was composed of the imagination and locomotion tests. The subject was now led from the home stool to the position of one of the objects, which had a second pointer appa-

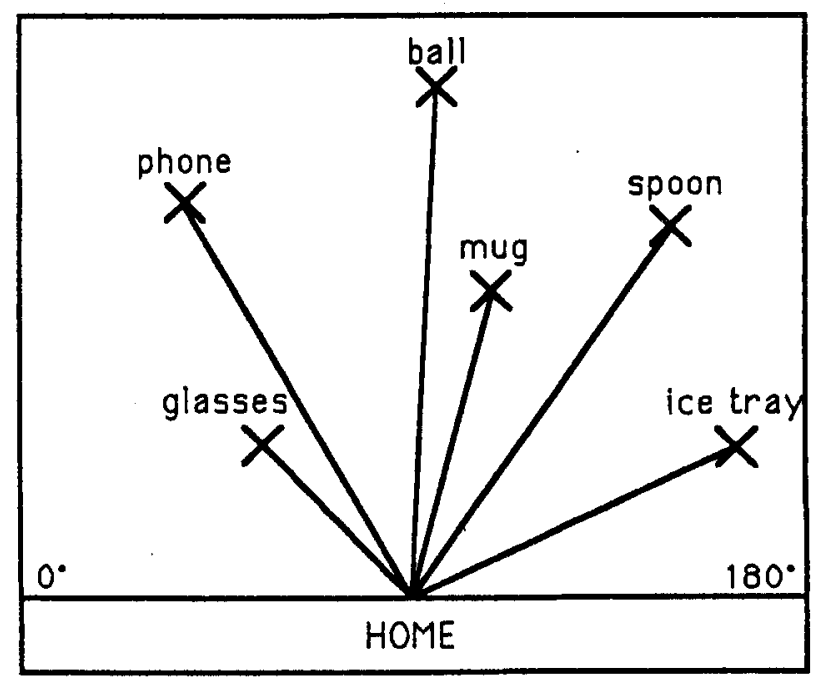

Figure 9. The locations of the objects used in the spatial updating task. (Home represents the origin from which the subject locomoted to each of the target objects, which were located waist high on stools. The distance to the ball was $524 \mathrm{~cm}$.) ratus resting on the stool; the path taken was initially in the direction of the object but then curved smoothly so that the subject ended up at the stool facing the center of the work space, with the hand on the second pointer, as had been done at the home position. He or she then was then led back to the home stool and realigned with the hand on the pointer, then back to the object stool (by way of the $\mathrm{J}$-shaped path) and re-aligned once again with the hand on the pointer there. In the locomotion condition, the subject was then asked to point to each of the remaining objects from this new position as quickly and accurately as possible, and was timed as before. In the imagination condition, the subject did not respond from the new position, but was led back once more to the home stool and aligned with the pointer there. He or she was then asked to imagine being back at the previous position and to point to each object as if standing aligned with that stool and pointer. For both tests, objects were tested in random order and then retested in random order.

Three of the subjects in each group had the locomotion test before the imagination test and two were tested in the reverse order. Three in each group had the spoon as the location of the locomotion test and the phone as the location of the imagination test; the remainder had the reverse conditions. From the location of the spoon, the correct response angles were $-10^{\circ}, 64^{\circ}, 73^{\circ}, 93^{\circ}$, and $120^{\circ}$ relative to direct left (with the subject facing the stool); from the location of the phone these angles were $63^{\circ}, 92^{\circ}, 105^{\circ}$, $112^{\circ}$, and $160^{\circ}$. Test location (spoon or phone) and test order were counterbalanced with type of test as equally as possible.

\section{Results and Discussion}

Analyses of the response times and errors in the initial 25 auditorily cued pointing trials revealed no systematic group effects. The mean response time (RT) was $3.2 \mathrm{~s}$ for the congenitally blind and $2.3 \mathrm{~s}$ for the sighted; there was no significant difference in an ANOVA on group and target position (although the target position effect was significant). Absolute angular errors also did not show a group effect, averaging $13.5^{\circ}$ for the blind and $10.6^{\circ}$ for the sighted (nor was there a position effect).

The main results from this study were absolute errors and response times for each test: baseline, locomotion, and imagination. These were obtained for each group. Figure 10 shows the individual subjects' data organized by group and condition. The group means are presented in Table 8, along with comparable means from Rieser et al. (1986). (Rieser et al. collected baseline data twice, once for locomotion and once for imagination. The given baseline is a mean of those reported, which were very similar.)

Rieser et al. (1986) found that the congenitally blind subjects showed increments in RT, relative to the baseline, for both the locomotion and imagination tests, whereas the sighted and adventitiously blind showed increments only for imagination. The implication was that the latter two groups, but not the congenitally blind, were able to imaginally update the target locations during locomotion. Rieser et al. also found that the error pattern was similar to that of the RTs, with the blind showing a far larger increase in the locomotion condition, relative to the baseline, than the other two groups.

Our mean RTs exhibit some of the same trends. However, these means are somewhat misleading, as can be seen when 


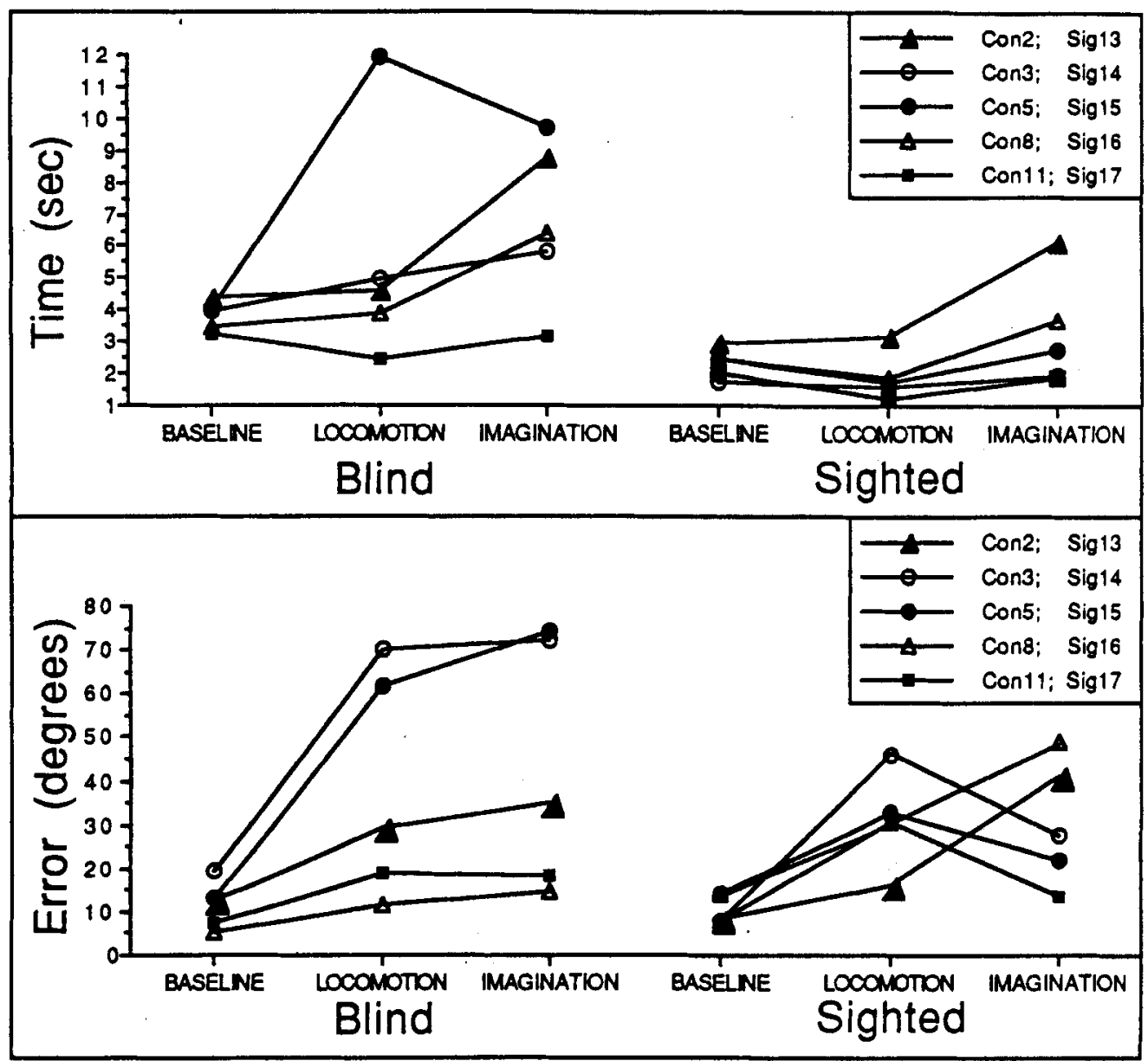

Figure 10. Results of the spatial updating task. (Response latency [upper panel] and error [lower panel] are given as a function of task and group. The individual subjects are identified by number and label: Con = congenitally blind; $\mathrm{Sig}=$ sighted.)

the individual-subject data in Figure 10 are examined. Much of the increase among the blind subjects between baseline and locomotion was due to one subject (whose blindness was caused by retrolental fibroplasia); 3 subjects showed very small (or in one case, negative) effects. Four of the 5 blind subjects showed greater RTs for imagination than locomotion, suggesting that some degree of updating had occurred during locomotion. Furthermore, the difference between locomotion and imagination was about the same for the blind as for the sighted.

As might be expected, given the overall similarity of the RT pattern for blind and sighted subjects. an overall ANOVA on group and test did not show a significant interaction. $F(2,16)=1.52, p=.25$. Similarly, the interaction was not significant when baseline was compared individually with locomotion and imagination, although in the latter case, it was marginal, $F(1,8)=3.08, p=.12$, indicating a trend for the baseline versus imagination difference to be greater for the blind. The ANOVA did show a main effect of group, $F(1,8)=7.58, p<.05$, with slower responses for the blind. The effect of test was also significant, as expected, $F(2,16)=4.41, p<.05$. The baseline test was performed significantly faster than the imagination test, $F(1,8)=$ 11.42, $p<.01$, but not the locomotion test $(F<1)$. The same ANOVA on error showed a main effect of test, $F(2$. $16)=13.83, p<.001$. The baseline test was significantly more accurate than either the locomotion or imagination tests, $F \mathrm{~s}(1,8)=17.40$ and $19.86, p s<.01$. The latter tests did not differ $(F<1)$.

It is possible but unlikely that minor procedural and empirical differences between this study and that of Rieser et al. (1986) could account for the differences between the results of the two studies. We assessed baseline performance only once, and we used only two tasks rather than three (Rieser et al. included a second locomotion task). We assessed locomotion and imagination from different station points, which had slightly different response requirements. Our subjects were slower in responding than their subjects and were slightly more accurate. suggesting that a speedaccuracy trade-off might have been a factor. Whatever the impact of these slight procedural differences. however, our blind subjects did show evidence of updating in locomotion. and 3 of them showed patterns quite similar to those of the sighted. 
Table 8

Response Times (RTs) and Errors (in Degrees) for Experiment 2 and Rieser, Guth, and Hill (1986) by Group (Blind or Sighted) and Test Condition

\begin{tabular}{|c|c|c|c|c|c|c|}
\hline \multirow[b]{2}{*}{ Measure } & \multicolumn{3}{|c|}{ Blind } & \multicolumn{3}{|c|}{ Sighted } \\
\hline & Baseline & $\mathrm{LM}$ & $\mathrm{IM}$ & Baseline & LM & IM \\
\hline \multicolumn{7}{|c|}{ Experiment 2} \\
\hline $\begin{array}{l}\text { RT } \\
\text { Error }\end{array}$ & $\begin{array}{r}3.8 \\
11.4\end{array}$ & $\begin{array}{r}5.6 \\
38.4\end{array}$ & $\begin{array}{r}6.8 \\
42.9\end{array}$ & $\begin{array}{r}2.3 \\
10.4\end{array}$ & $\begin{array}{r}2.1 \\
31.4\end{array}$ & $\begin{array}{r}3.3 \\
30.7\end{array}$ \\
\hline \multicolumn{7}{|c|}{ Rieser et al. (1986) } \\
\hline $\begin{array}{l}\text { RT } \\
\text { Error }\end{array}$ & $\begin{array}{r}0.8 \\
13.2\end{array}$ & $\begin{array}{r}1.7 \\
41.4\end{array}$ & $\begin{array}{r}2.2 \\
67.7\end{array}$ & $\begin{array}{r}0.7 \\
14.9\end{array}$ & $\begin{array}{r}0.6 \\
23.9\end{array}$ & $\begin{array}{r}1.7 \\
40.1\end{array}$ \\
\hline
\end{tabular}

Note. From "Sensitivity to Perspective Structure While Walking Without Vision," by J. J. Rieser, D. A. Guth, and E. W. Hill, 1986, Perception, 15, pp. 173-188. Copyright 1986 by Pion Limited. Reprinted by permission. $\mathrm{LM}=$ locomotion test condition; $\mathrm{IM}=$ imagination test condition.

The ability of the blind to represent the locations of the objects in space is indicated by the individual-subject graphs in Figure 11, which show the subjects' pointer response as a function of the actual response for a sample of subjects and conditions. The dashed line in each panel represents correct responding; the two solid lines are regression lines fitted to the data of the imagination and locomotion conditions. The best subject of all, Con 8 , was congenitally blind; interestingly, he had lost his vision through retrolental fibroplasia, which is widely thought to be associated with deficits in spatial ability. (However, recent experimental evidence reported by Dodds, Hellawell, \& Lee, 1991, calls this into question.)

\section{General Discussion}

\section{Processes Underlying Navigation in Sparse Environments}

The present experiments provide useful data on the skill with which human subjects perform nonvisual path integration and are informative about the underlying processes. We first reconsider, in light of the present findings, the hypothesis that individuals navigating without vision simply update a homing vector while traversing an outbound path (e.g., Fujita et al., 1990; Müller \& Wehner, 1988). According to this hypothesis, because the outbound path is not stored in memory, updating the homing vector should not depend on the distance or time taken to reach any given location. The finding in connection with the retrace-completion task, that the latency to initiate the return toward the origin increased with the complexity of the outbound path (Figure 8), is thus incompatible with updating the homing vector. The fact that increasing path complexity increases return latency suggests that subjects form some representation of the outbound path in memory. Furthermore, the fact that subjects can retrace or complete a path at will indicates that they are able to maintain a history of their route even when the situation might call for a shortcut back to the origin.
Additional evidence is provided by Fujita et al. (1993; see also Klatzky, Loomis, Golledge, Fujita, et al., 1990), who present a model-based approach that allows one to make inferences about the representation underlying the triangle completion task. The model assumes that subjects retain a history of the segments and turns they have traveled. They represent the lengths of segments and the values of turns, but they tend to do so with error. In particular, values larger than the average physical values tend to be represented as smaller than they are, whereas relatively small values tend to be represented as larger than they are. As was indicated in the introduction, such regression toward the mean (which is also obtained in direct estimates and reproductions of segments) is inconsistent with a step-by-step updating of one's position in space and discarding of past history.

The effects of pathway complexity further indicate that configural properties of a route produce sources of error beyond those attributable to errors in representing segment parameters (as described by the Fujita et al., 1993, model). The apparently disorienting effect of the crossover in Configuration 11 of the retrace-completion task, as indicated by the extremely poor performance, is particularly striking.

\section{Visual Experience as a Factor in Discriminating Groups}

We now turn to the effects of visual experience in our tasks. In Experiment 1, using a variety of simple and complex navigation tasks, we found no significant differences among our subject groups. Examination of individual subjects shows, in fact, that some of our best performances came from congenitally blind subjects, and some of our worst came from blindfolded, sighted individuals. ${ }^{3}$

It is not surprising that group differences were not found for some of the simpler locomotion tasks, such as turn and distance reproduction, for they can be performed on the basis of a trace of the traveled route. One might expect to see differences emerge between those subjects with and without visual experience on tasks that require computation of new trajectories, such as completing a multisegment pathway by a shortcut. Still, these expectations were not met.

Our failure to find group differences in Experiment 1 led us to conduct the experiment using the more difficult task of Rieser et al. (1986), which requires the subject to develop a representation of multiple locations. However, we did not replicate their finding that the congenitally blind were significantly worse in both accuracy and response latency than the sighted and adventitiously blind in the condition involv-

\footnotetext{
${ }^{3}$ However, it should be noted that a linear discriminant analysis was able to differentiate among the three groups at well above chance (Klatzky, Golledge, Loomis, Cicinelli, \& Pellegrino, 1993). The two variables used in the discriminant function were both measures of performance involving locomotion on multisegment pathways rather than simple reproduction of a movement. This finding is consistent at least with the hypothesis that the blind and sighted differ most on tasks involving spatial inference rather than proprioceptive memory.
} 

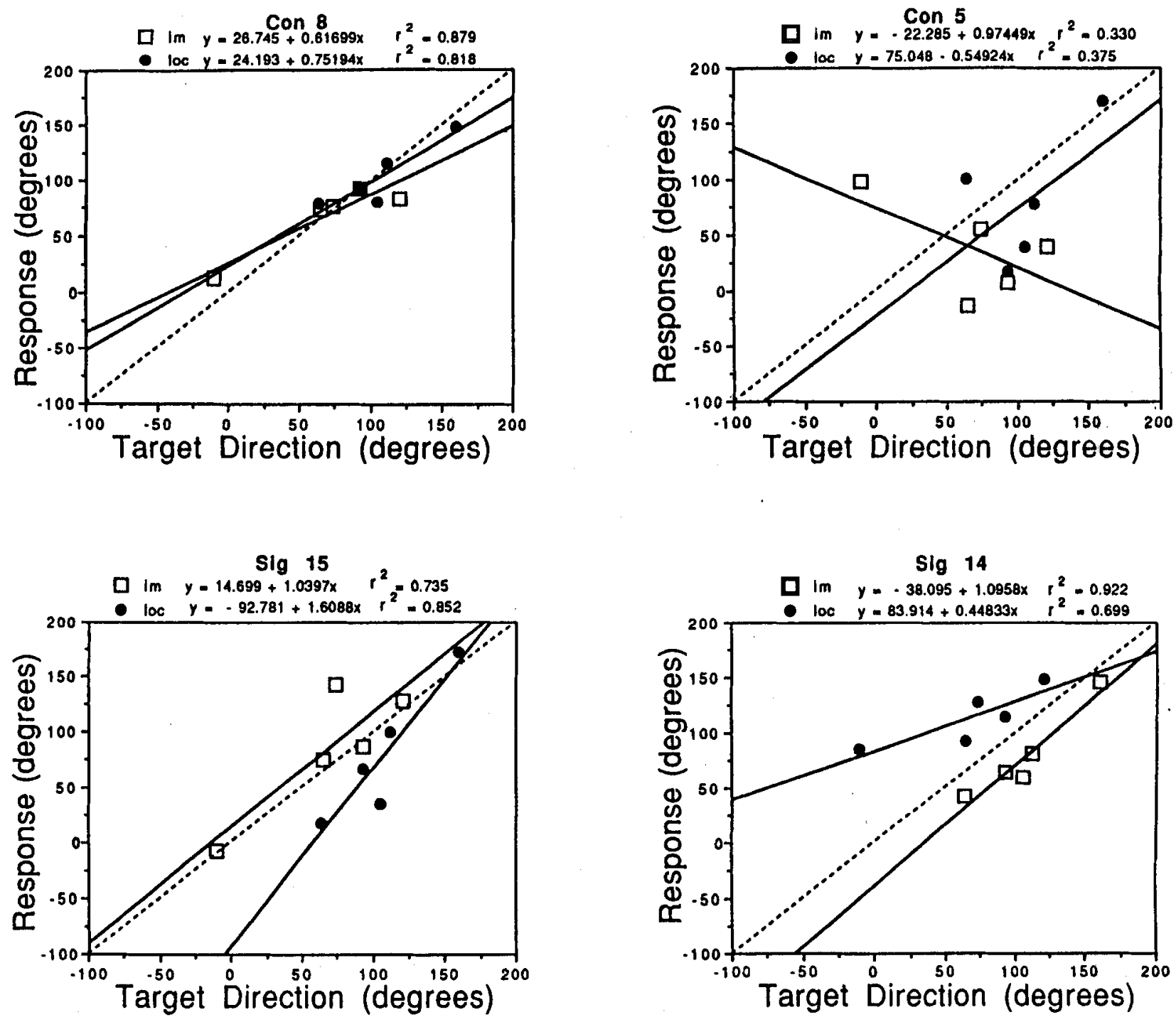

Figure 11. Results of four selected individuals in the spatial updating task. (The subject's pointing response [in degrees] is plotted against the correct target direction [in degrees]; the dashed lines represent correct responding. Data from the locomotion [loc] and imagination [im] conditions are given by the solid and open symbols, respectively. The solid lines are the regression lines for predicting the response from the target direction. The regression equations for these lines are given above each panel. Con = congenitally blind; $\mathrm{Sig}=$ sighted.)

ing pointing following locomotion; instead we found only a trend in that direction in our comparison of the sighted and congenitally blind. As in Experiment 1, heterogeneity among the blind subjects was the rule, with one congenitally blind subject performing very poorly like those in Rieser et al.'s group and another performing very well: interestingly, both subjects had lost their sight as the result of retrolental fibroplasia. From the results of this task, we conclude that at least some of the congenitally blind observers are able to update the locations of known objects during locomotion as well as blindfolded sighted observers.

One question that remains is why some studies show a group difference and others do not, especially when they involve the same task and method. We believe that a critical issue is the manner in which the blind subjects are selected. Because many studies comparing blind and sighted obtain their populations through schools and other agencies for the blind, and because many of these adult clients are unable to travel independently, there has probably been some bias in such studies toward selecting subjects with mobility skills worse than average. Although we too obtained our subjects largely with the assistance of the Braille Institure, we sought subjects who were able to travel independently; accordingly, our selection procedure may have been biased toward subjects with better-than-average mobility skills. How one chooses to do this type of research depends on one's implicit 
theory of the connection between mobility skill and spatial ability.

On the one hand, individuals who lack early visual experience may fail to develop the spatial abilities requisite for independent travel; in this case, including enough subjects like this in the research design will lead to the correct conclusion that vision is important for the development of spatial competence. On the other hand, it might be that blind subjects with poor mobility skills are those whose personality characteristics inhibit them from attempting independent travel. If independent travel, not prior visual experience, is the causative factor that promotes the development of spatial ability, then including such individuals in an experiment will falsely predispose the research toward the conclusion that visual experience is important in the development of spatial ability. Because studies have differed in the manner in which subjects were recruited, and because sample sizes have often been quite small, we conclude that research on the question of how visual experience affects spatial ability has not been as definitive as it might be. Until there is some reasoned basis for selecting subjects without bias, the question of exactly which aspects of the ability to navigate without vision are influenced by prior visual experience will remain unsettled.

\section{References}

Baker, R. R. (1981). Human navigation and the sixth sense. London: Hodder and Stoughton.

Barber, P. O., \& Lederman, S. J. (1988). Encoding direction in manipulatory space and the role of visual experience. Journal of Visual Impairment and Blindness, 82, 99-106.

Barlow, J. S. (1964). Inertial navigation as a basis for animal navigation. Journal of Theoretical Biology, 6, 76-117.

Beritoff, J. S. (1965). Neural mechanisms of higher vertebrate behavior. (W. T. Liberson, Trans. and Ed.) Boston: Little, Brown.

Bower, T. G. R. (1977). A primer of infant development. New York: Freeman.

Brambring, M. (1976). The structure of haptic space in the blind and sighted. Psychological Research, 38, 283-302.

Byrne, R. W., \& Salter, E. (1983). Distances and directions in the cognitive maps of the blind. Canadian Journal of Psychology, 37, 293-299.

Casey, S. M. (1978). Cognitive mapping by the blind. Journal of Visual Impairment and Blindness, 72, 297-301.

Dodds, A. G., \& Carter, D. D. C. (1983). Memory for movement in blind children: The role of previous visual experience. Journal of Motor Behavior, 15, 343-352.

Dodds, A. G., Hellawell, D. J., \& Lee, M. D. (1991). Congenitally blind children with and without retrolental fibroplasia: Do they perform differently? Journal of Visual Impairment and Blindness, 85, 225-227.

Dodds, A. G., Howarth, C. I., \& Carter, D. C. (1982). The mental maps of the blind: The role of previous visual experience. Journal of Visual Impairment and Blindness, 76, 5-12.

Etienne, A. S. (1992). Navigation of a small mammal by dead reckoning and local cues. Current Directions in Psychological Science, 1, 48-52.

Foulke, E. (1971). The perceptual basis for mobility. American Foundation for the Blind Research Bulletin, 23, 1-8.

Foulke, E. (1982). Perception, cognition, and the mobility of blind pedestrians. In M. Potegal (Ed.), Spatial abilities: Development and physiological foundations (pp. 55-76). San Diego, CA: Academic Press.

Fujita, N., Loomis, J. M., Klatzky, R. L., \& Golledge, R. G. (1990). A minimal representation for dead-reckoning navigation: Updating the homing vector. Geographical Analysis, 22, 326-335.

Fujita, N., Klatzky, R. L., Loomis, J. M., \& Golledge, R. G. (1993). The encoding-error model of pathway completion without vision. Manuscript submitted for publication.

Gallistel, C. R. (1990). The organization of learning. Cambridge, MA: MIT Press.

Heller, M. A., \& Kennedy, J. M. (1990). Perspective taking, pictures, and the blind. Perception \& Psychophysics, 48, 459-466.

Herman, J. F., Chatman, S. P., \& Roth, M. A. (1983). Cognitive mapping in blind people: Acquisition of spatial relationships in a large-scale environment. Journal of Visual Impairment and Blindness, 77, 161-166.

Hollins, M., \& Kelley, E. K. (1988). Spatial updating in blind and sighted people. Perception \& Psychophysics, 43, 380-388.

Howard, I. P. (1982). Human visual orientation. New York: Wiley. Howard, I. P., \& Templeton, W. B. (1966). Human spatial orientation. New York: Wiley.

Kerr, N. (1983). The role of vision in "visual imagery" experiments: Evidence from the congenitally blind. Journal of Experimental Psychology: General, 112, 265-277.

Klatzky, R. L., Golledge, R. G., Loomis, J. M., Cicinelli, J. G., \& Pellegrino, J. W. (1993). Performance of blind and sighted in manipulatory and ambulatory space. Manuscript submitted for publication.

Klatzky, R. L., Loomis, J. M., Golledge, R. G., Cicinelli, J. G., Doherty, S., \& Pellegrino, J. W. (1990). Acquisition of route and survey knowledge in the absence of vision. Journal of Motor Behavior, 22, 19-43.

Klatzky, R. L., Loomis, J. M., Golledge, R. G., Fujita, N., \& Pellegrino, J. W. '(1990, November). Navigation without vision by blind and sighted. Paper presented at the annual meeting of the Psychonomics Society, New Orleans, LA.

Kuipers, B. (1978). Modeling spatial knowledge. Cognitive Science, 2, 129-153.

Kuipers, B. (1982). The "map in the head" metaphor. Environment and Behavior, 14, 202-220.

Landau, B. (1988). The construction and use of spatial knowledge in blind and sighted children. In J. Stiles-Davis, M. Kritchevsky, \& U. Bellugi (Eds.), Spatial cognition: Brain bases and development (pp. 343-371). Hillsdale, NJ: Erlbaum.

Landau, B., Spelke, E., \& Gleitman, H. (1984). Spatial knowledge in a young blind child. Cognition, J6, 225-260.

Lederman, S. J., Klatzky, R., \& Barber, P. (1985). Spatial- and movement-based heuristics for encoding pattern information through touch. Journal of Experimental Psychology: General, $114,33-49$.

Liben, L. (1988). Conceptual issues in the development of spatial cognition. In J. Stiles-Davis, M. Kritchevsky, \& U. Bellugi (Eds.), Spatial cognition: Brain bases and development (pp. 167-194). Hillsdale, NJ: Erlbaum.

Lynch, K. (1960). The image of the city. Cambridge, MA: M.I.T. Press.

Millar, S. (1976). Spatial representation by blind and sighted children. Journal of Experimental Child Psychology, 12, 460-479.

Millar, S. (1981). Self-referent and movement cues in coding spatial location by blind and sighted children. Perception, 10, 255264.

Mittelstaedt, M. L., \& Glasauer, S. (1991). Idiothetic navigation in gerbils and humans. Zoologische Jahrbucher Abteilung für allgemeine Zoologie und Physiologie der Tiere, 95, 427-435.

Mittelstaedt, H., \& Mittelstaedt, M. L. (1982). Homing by path 
integration. In F. Papi \& H. G. Wallraff (Eds.), Avian navigation (pp. 290-297). New York: Springer.

Müller, M., \& Wehner, R. (1988). Path integration in desert ants, Cataglyphis fortis. Proceedings of the National Academy of Sciences, 85, 5287-5290.

Passini, R., Proulx, G., \& Rainville, C. (1990). The spatio-cognitive abilities of the visually impaired population. Environment and Behavior, 22, 91-116.

Pitman, G. (1962). Inertial guidance. New York: Wiley.

Potegal, M. (1982). Vestibular and neostriatal contributions to spatial orientation. In M. Potegal (Ed.), Spatial abilities: Development and physiological foundations (pp. 361-387). San Diego, CA: Academic Press.

Potegal, M. (1985). The vestibular navigation hypothesis: A progress report. In P. Ellen \& C. Thinus-Blanc (Eds.), Cognitive processes and spatial orientation in animal and man: Vol. 2. Neurophysiology and developmental aspects (pp. 28-34). Dordrecht, The Netherlands: Martinus Nijhoff.

Rieser, J. J. (1990). Development of perceptual-motor control while walking without vision: The calibration of perception and action. In H. Bloch \& B. I. Bertenthal (Eds.), Sensory-motor organizations and development in infancy and early childhood (pp. 379-408). Norwell, MA: Kluwer Academic.

Rieser, J. J., Guth, D. A., \& Hill, E. W. (1982). Mental processes mediating independent travel: Implications for orientation and mobility. Journal of Visual Impairment and Blindness, 76, 213218.

Rieser, J. J., Guth, D. A., \& Hill, E. W. (1986). Sensitivity to perspective structure while walking without vision. Perception, $15,173-188$.

Rieser, J. J., Hill, E. W., Talor, C. R., Bradfield, A., \& Rosen, S. (1992). Visual experience, visual field size, and the development of nonvisual sensitivity to the spatial structure of outdoor neighborhoods explored by walking. Joumal of Experimental Psy- chology: General, 121, 210-221.

Rieser, J. J., Lockman, J. J., \& Pick, H. L. Jr. (1980). The role of visual experience in knowledge of spatial layout. Perception \& Psychophysics, 28, 185-190.

Schiesser, E. R. (1986). Principles of navigation. In C. Belove (Ed.), Handbook of modern electronics and electrical engineering. New York: Wiley.

Senden, M. von. (1960). Space and sight. (P. Heath, Trans.). Free Press of Glencoe, New York. (Original work published 1932)

Strelow, E. R. (1985). What is needed for a theory of mobility: Direct perception and cognitive maps-lessons from the blind. Psychological Review, 92, 226-248.

Veraart, C., \& Wanet-Defalque, M. C. (1987). Representation of locomotor space by the blind. Perception \& Psychophysics, 42, 132-139.

von Saint Paul, U. (1982). Do geese use path integration for walking home? In F. Papi \& H. G. Wallraff (Eds.), Avian navigation (pp. 296-307). New York: Springer.

Wehner, R., \& Wehner, S. (1986). Path integration in desert ants. Approaching a long-standing puzzle in insect navigation. Monitore Zoologico Italiano, 20, 309-331.

Welsh, R., \& Blasch, B. B. (Eds.). (1980). Foundations of orientation and mobility. New York: American Foundation for the Blind.

Worchel, P. (1951). Space perception and orientation in the blind. Psychological Monographs, 65, 1-28.

Yamamoto, T. (1991). A longitudinal study of the development of spatial problem solving ability in the early blind. Japanese Journal of Psychology, 61, 413-417.

Received June 4, 1991 Revision received July 13, 1992 Accepted July 27, 1992 